\title{
OH PLIF Visualization of a Premixed Ethylene-fueled Dual-Mode Scramjet Combustor
}

\author{
Luca M. L. Cantu*, Emanuela C. A. Gallo ${ }^{\dagger}$, Andrew D. Cutler*, \\ The George Washington University, Mechanical and Aerospace Engineering, \\ Washington, DC, 20052 \\ Paul M. Danehy ${ }^{\S}$ \\ NASA Langley Research Center, Advanced Measurements and Data Systems Branch, \\ Hampton, VA, 23681 \\ Craig T. Johansen ${ }^{* *}$ \\ University of Calgary, Mechanical and Manufacturing Engineering \\ Calgary, $A B, T 2 N$ 1N4, Canada \\ Robert D. Rockwell ${ }^{\dagger \dagger}$, Christopher P. Goyne ${ }^{\star \star}$ James C. McDaniel ${ }^{\S \S}$ \\ University of Virginia, Mechanical and Aerospace Engineering, \\ Charlottesville, VA, 22904
}

\begin{abstract}
Hydroxyl radical (OH) planar induced laser fluorescence (PLIF) measurements have been performed in a small-scale scramjet combustor at the University of Virginia Aerospace Research Laboratory at nominal simulated Mach 5 enthalpy. OH lines were carefully chosen to have fluorescent signal that is independent of pressure and temperature but linear with mole fraction. The OH PLIF signal was imaged in planes orthogonal to and parallel to the freestream flow at different equivalence ratios. Flameout limits were tested and identified. Instantaneous planar images were recorded and analyzed to compare the results with width increased dual-pump enhanced coherent anti-Stokes Raman spectroscopy (WIDECARS) measurements in the same facility and large eddy simulation/Reynolds average Navier-Stokes (LES/RANS) numerical simulation. The flame angle was found to be approximately 10 degrees for several different conditions, which is in agreement with numerical predictions and measurements using WIDECARS. Finally, a comparison between NO PLIF non-combustion cases and OH PLIF combustion cases is provided: the comparison reveals that the dominant effect of flame propagation is freestream turbulence rather than heat release and concentration gradients.
\end{abstract}

* Ph.D. Candidate. Student Member AIAA

$\dagger$ Ph.D. Candidate. Student Member AIAA

$¥$ Professor. Associate Fellow AIAA

$\S$ Research Scientist. Associate Fellow AIAA

** Assistant Professor. Senior Member AIAA

$\dagger$ Senior Scientist. Member AIAA

$\$$ Associate Professor. Associate Fellow AIAA

$\S \S$ Professor. Associate Fellow AIAA 


\section{Introduction}

Planar laser induced fluorescence (PLIF) ${ }^{1}$ is an instantaneous, spatially-resolved optical measurement technique that involves molecular excitation for both quantitative measurements and flow visualization. A laser, first expanded into a planar sheet and then focused in the measurement region, is tuned to a specific absorption transition of the target molecule; for a certain finite time (depending on the laser pulse duration and the fluorescence life time), a spontaneous emission of radiation from an upper energy level (fluorescence) is emitted from the illuminated region. When the molecule emits energy at the same wavelength the process is called resonance fluorescence. Usually some energy can be lost due to molecular collisions, a process known as collisional quenching. Collisions may also cause rotational and vibrational energy transfers to other adjacent states, resulting in additional spontaneous fluorescence emission lines at longer wavelengths compared to the laser. A schematic representation of this process is shown in the energy diagram in Figure 1.

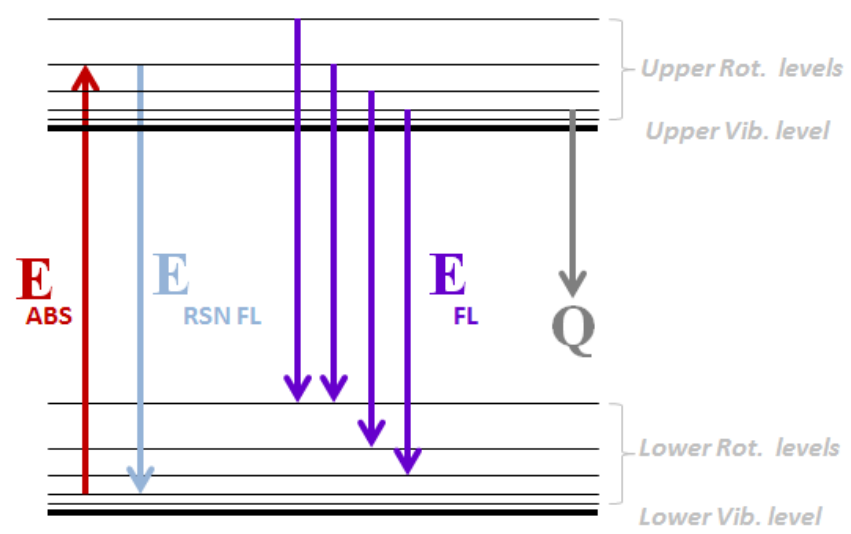

Figure 1: LIF energy diagram

Due to its capability to detect fluorescence of one flame radical or minor species at a time in part per million ranges, PLIF is a very suitable technique in hot, high-speed flow environments. ${ }^{2,3,4,5}$ Several studies used the PLIF technique for visualization of the high-speed combustion and mixing processes: Hartfield at al. ${ }^{6}$ and later Donohue et al. ${ }^{7}$ performed a quantitative mixing study using iodine PLIF. Takahashi et al. ${ }^{8}$ investigated mole fraction distribution and density using acetone as tracer. Rasmussen et al. ${ }^{9}$ used $\mathrm{OH}$ and $\mathrm{CH}_{2} \mathrm{O}$-PLIF to study a cavity flame stabilization mechanism. Donbar et al. ${ }^{10}$ used OH-PLIF in an ethylene and JP-7 combustion study. Gaston et al. ${ }^{11}$ used PLIF to determine mixing performance parameters and performance of $\mathrm{H}_{2}$ fuel injectors using PLIF of NO. Gruber et al. ${ }^{12}$ investigated a supersonic cavity design using $\mathrm{NO}$ and $\mathrm{OH} \mathrm{PLIF}$, injecting reacting and non-reacting ethylene. Johansen et al. ${ }^{13}$ and later McRae et al. ${ }^{14}$ investigated OH PLIF imaging in a $\mathrm{H}_{2}$-air fueled dual mode-scramjet at the University of Virginia.

In this paper, a dual-mode scramjet fueled with ethylene $\left(\mathrm{C}_{2} \mathrm{H}_{4}\right)$ is investigated in the same University of Virginia facility. A frequency-doubled tunable laser was tuned at $283 \mathrm{~nm}$ to excite a specific absorption transition of $\mathrm{OH}$; images of $\mathrm{OH}$ fluorescence were recorded both perpendicular to the freestream (cross-plane view) and parallel to the freestream (stream-wise view); 4 planes were recorded for the cross-plane view at the same location and test conditions of the subsequent particle image velocity (PIV) ${ }^{15}$ and width enhanced coherent anti-Stokes Raman scattering (WIDECARS $)^{16}$ measurements of $\mathrm{C}_{2} \mathrm{H}_{4}$-air combustion in the same facility. Scans through all the imaging planes were also recorded for all the facility conditions. The stream-wise view consisted of 3 consecutive images overlapped by $1 / 5$ and then combined into a single composite image. 


\section{A. Facility}

\section{Experimental Setup}

All the experiments were performed at the University of Virginia Supersonic Combustion Facility (UVaSCF), a small scale, vertically oriented, electrically heated, continuous flow, optically accessible, direct-connect scramjet wind tunnel, described in detail by Rockwell et al. ${ }^{17}$ and Krauss et al. ${ }^{18,19}$ The UVaSCF uses a Mach 2 nozzle to simulate a Mach 5 flight condition (with stagnation pressure $p_{0}=300 \mathrm{kPa}$ and temperature $T_{0}=1200 \mathrm{~K}$ respectively) in the engine-shaped test section; the flow-path geometry is shown in Figure 2.

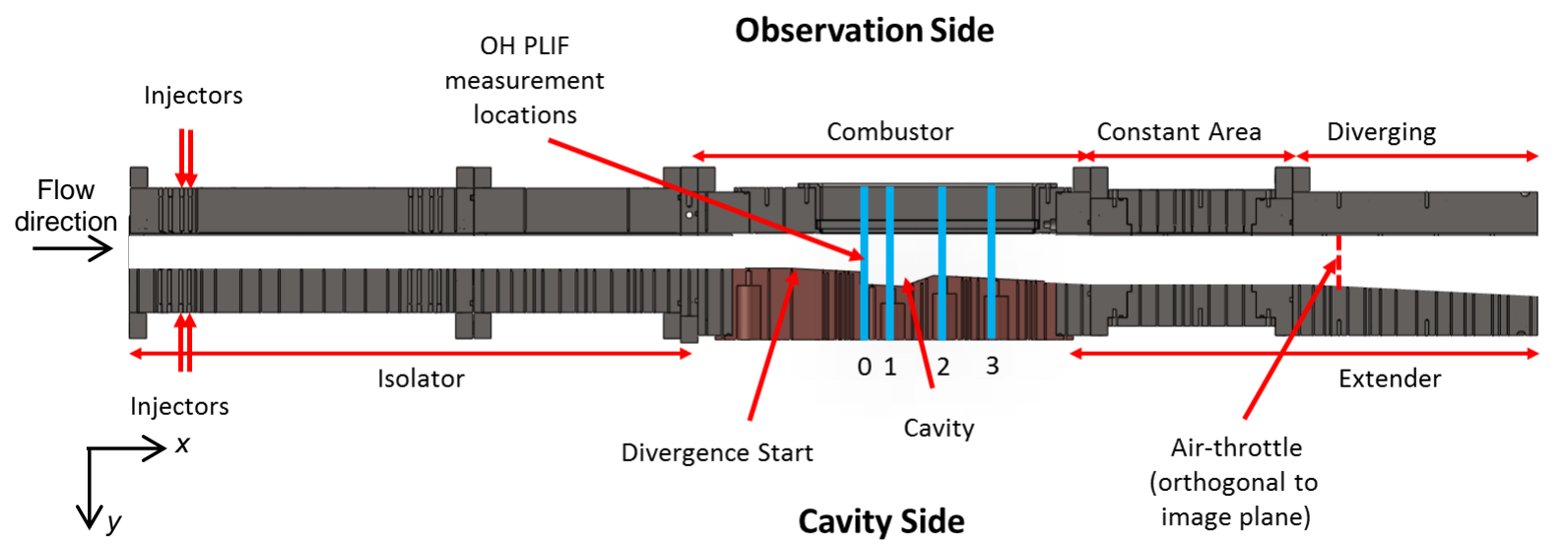

Figure 2. The scramjet duct geometry, injectors' location and test plane (blue line) for OH PLIF measurements

The scramjet mode ${ }^{20}$ consisted of isolator, combustor, and extender sections. The constant-area-isolator section (44.5 $H$ long, where $H=9.04 \mathrm{~mm}$, the height of the combustor cavity) was placed ahead of the combustor to contain the combustion induced shock train. ${ }^{21}$ Thus allowing the facility to operate at a higher maximum equivalence ratios:

$$
\mathrm{ER}=1.43 \frac{\chi_{\text {fuel }}}{1-\chi_{\text {fuel }}}
$$

Two span-wise rows (spaced $6.22 \mathrm{~mm}$ apart) of three injectors per wall (1.27 cm apart, $1.24 \mathrm{~mm}$ diameter), perpendicular to and flush with the walls, were located at $4.21 \mathrm{H}$ and $4.90 \mathrm{H}$ downstream of the isolator entrance. ${ }^{22}$ Ethylene $\left(\mathrm{C}_{2} \mathrm{H}_{4}\right)$ fuel was injected into the freestream at different ERs according to the values of the best cases found in a similar, previous NO PLIF experiment. ${ }^{23}$ The large distance between the injectors and the combustor was chosen such that the fuel could properly premix before igniting in the cavity flame holder.

The combustor section diverged at an angle of $2.9^{\circ}$ beginning $8.78 \mathrm{H}$ from the end of the isolator. A cavity (height $H=9.04 \mathrm{~mm}$, length $L=5.89 \mathrm{H}$, and $22.5^{\circ}$ closeout angle) was placed in the combustor, $14.69 \mathrm{H}$ from the end of the isolator, to enhance the residence time of oxidizer and radicals for flame-holding purposes. ${ }^{24}$ Two UV grade fused silica windows were mounted in the parallel side walls to provide optical access for the cross-plane laser sheet (described in Section III) for flow visualization. An additional UV grade fused silica window was mounted on the observation side ( $x-z$ plane), opposite the cavity, providing optical access for the stream-wise view tests.

All measurements were taken at measurement planes downstream of the cavity step, which is defined as $x / H=0$ (plane 0 ). Measurement planes 1-3 correspond to $x / H$ positions of $1.5,4$, and 8 , respectively. The extender was divided into two sections: a constant area section, $16.47 \mathrm{H}$ long, and a diverging section, $18.92 \mathrm{H}$ long, angled by $2.9^{\circ}$ on the cavity side wall. At $x / H=37.5$, near the beginning of the divergent extender section, pressurized air was injected into the flow from a pair of slots located in both parallel side walls. Through use of this "air throttle" is possible to pressurize the upstream combustor and isolator independent of any combustion process. Thus by controlling the pressure of the air injected through the slots, it was possible to make adjustments to the location of the shock train inside the isolator. In order to examine the effect of shock train length on the combustion process, measurements were conducted with the shock train located by the back pressure due to combustion alone as well as with additional back pressure induced by the air-throttle. 


\section{B. Laser and Optics}

The laser and the optical system used in this experiment are mounted on a mobile cart, primarily used to perform coherent anti-Stokes Raman scattering (CARS) and width increased dual-pump enhanced (WIDE) CARS measurements, as described by Cutler et al..$^{25}$ and Gallo et al. ${ }^{26}$ respectively. With respect to the previously described systems, OH PLIF and NO PLIF ${ }^{23}$ were added to the capability of the laser cart.

Light from a $1064 \mathrm{~nm}, 20 \mathrm{~Hz}$ pulsed, Nd:YAG laser was frequency doubled to produce a $532 \mathrm{~nm}$ laser beam; this beam was used to pump a narrowband dye laser (Spectra Physics PDL-2) which excited a mixture of Rhodamine 590 and Rhodamine 610 laser dyes, optimized to obtain $567 \mathrm{~nm}$ light. The output of the dye laser was frequency doubled using a Spectra Physics Wavelength Extender (WEX) crystal module, which was removed from the WEX cabinet and placed on the mobile cart, to produce ultra violet (UV) light at $283 \mathrm{~nm}$. This light was used to excite the $\mathrm{Q}_{1}(8) \mathrm{OH}$ line. This transition was selected because it minimizes the temperature dependency of the PLIF signal ${ }^{27}$ and because it was also used in previous OH PLIF test campaigns in this facility. ${ }^{13,14}$ The UV light exiting the WEX module was sent first to a periscope containing dichroic mirrors, in order to separate the $283 \mathrm{~nm}$ light from the other colors of light and to change the polarization to be horizontal. Then the light passed through a horizontally-oriented Pellin-Broca prism to further separate the $283 \mathrm{~nm}$ beam from all the other residual wavelengths, which were sent to a beam dump. About $1 \%$ of the UV beam was sampled using a p-polarized reflection off an uncoated, quartz beam-splitter before exiting the laser cart: this reflection was split into two paths: the first one was sent to a photodiode connected to an oscilloscope to monitor the laser energy on a pulse to pulse basis; the second beam was directed to a lens-coupled fiber optic which was connected to a High Finesse WS-6L UV Wavemeter to continuously monitor the wavelength. It was important to continuously monitor the laser energy and wavelength since the PDL-2 and the WEX crystal were sensitive to temperature variations and needed to be optimized manually before each run. Figure 3 shows the optical setup close to the measurement location.

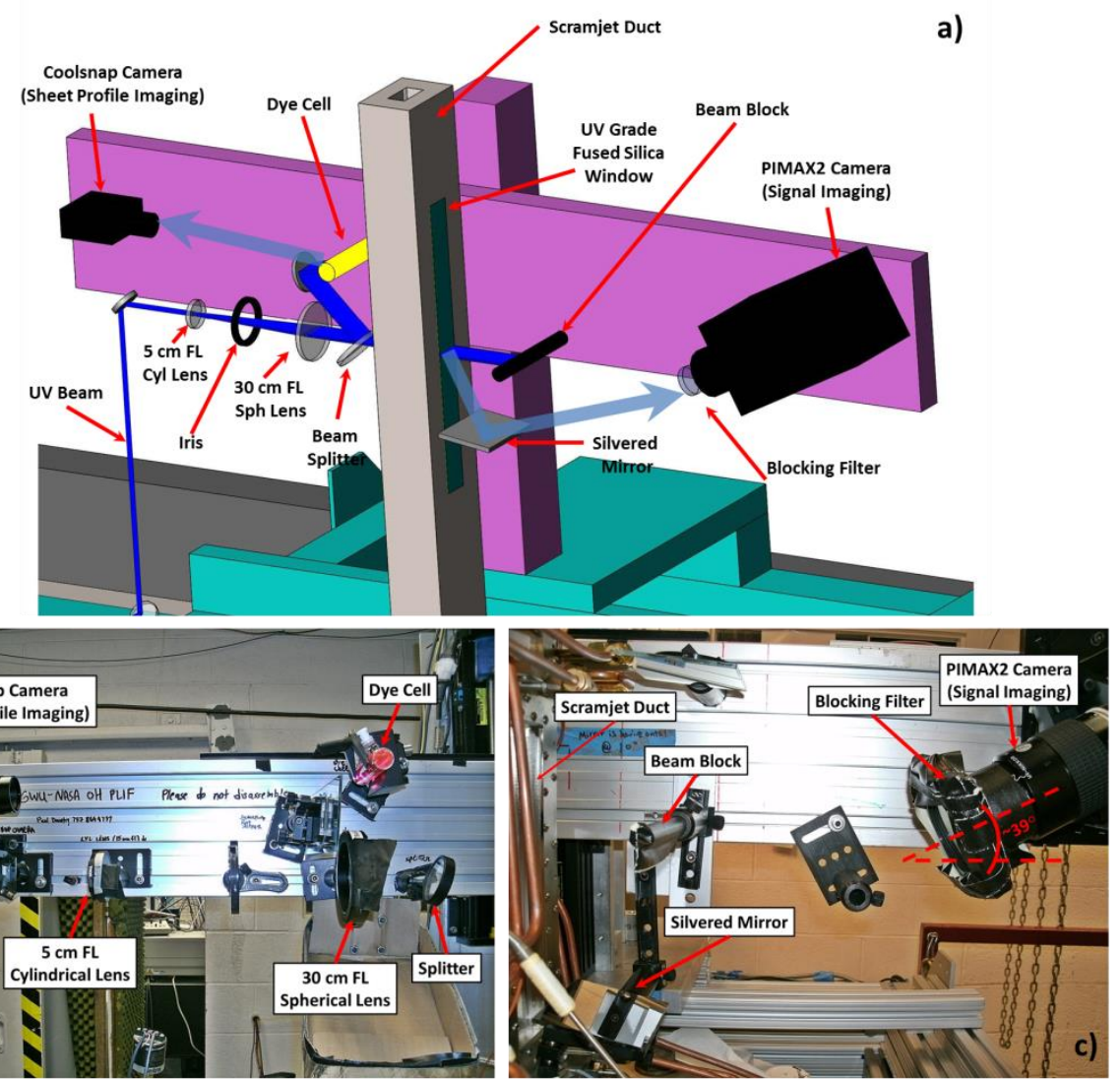

Figure 3. Optical setup cross-plane view configuration 1 in the test room; a) schematic; b) optical setup of the delivering system prior to the scramjet duct; c) the recording system after the scramjet duct. 
After exiting the cart, a UV mirror and a periscope sent the UV laser beam to a motorized vertical stage which allowed to change the height ( $x / H$ position) of the probed plane; the $283 \mathrm{~nm}$ light was first expanded into a sheet by a $5 \mathrm{~cm}$ focal length (FL) cylindrical lens then collimated in one direction by a $30 \mathrm{~cm}$ FL spherical lens which focused the other dimension of the laser beam to a thin waist roughly 100-300 (unmeasured) microns thick. A 50 mm diameter uncoated fused silica beam-splitter was placed in the beam path prior to the beam entering the tunnel and oriented with a p-reflection to yield a small amount ( 1\% energy) of the beam to illuminate a dye cell filled with a Rhodamine 590 solution. A Photometrics Coolsnap:cf camera imaged fluorescence from the dye cell to record images of laser sheet's spatial profile which were used during data processing to correct for laser energy fluctuations. The laser sheet, which was oriented perpendicular to the free-stream, was directed through two UV grade fused silica windows, mounted on sides of the tunnel and containing the flow. The beam ended its path on a beam block on the other side $(+z)$ of the duct. An Intensified Coupled Charged Device (ICCD) PIMAX2 camera was used to record the PLIF signal on 512x512 pixel array. Since it was not possible to have a direct perpendicular camera view of the laser sheet and tunnel physical constraints prevented the motorized stage from completing its run to the maximum height, two different configurations were used to record images at all the desired planes. In Configuration 1, the PIMAX2 was angled $\sim 39^{\circ}$ with respect to the laser sheet, viewing an image reflecting off a square silvered mirror placed as close as possible to the tunnel. Configuration 1, shown in Figure 3, allowed recording of images at the middle cavity plane (1), exit cavity plane (2), and the last combustor plane (3), pointing downstream through the flow. In Configuration 2, illustrated in Figure 4, a square silvered mirror was placed on top of the horizontal beam reflecting the UV light down where another square silvered mirror (placed $\sim 15 \mathrm{~cm}$ from the camera) directed the PLIF signal into the PIMAX2. Configuration 2 allowed recording of images at cavity step plane (0), repeating planes 1 and 2, but pointing upstream through the flow. A Scheimpflug mount was also used to better focus the image since the camera view was not perpendicular to the image plane. Geometrical distortions, resulting from these imaging configurations, were corrected during the data analysis procedure described in the Experimental Method section. A $283 \mathrm{~nm}$ (Semrock $2.54 \mathrm{~cm}$ diameter) blocking filter was placed in front of the lens of the PIMAX2 in order to eliminate scattered laser light. Resonant fluorescence was also blocked by this filter, helping reduce but not eliminate the effect of so-called radiative trapping (wherein emitted photons are reabsorbed by the gas) on the recorded PLIF signal. ${ }^{13,14}$ The PIMAX2 camera triggered the Coolsnap camera such that the images could be synchronized and a laser sheet correction could be applied for each single image acquired.

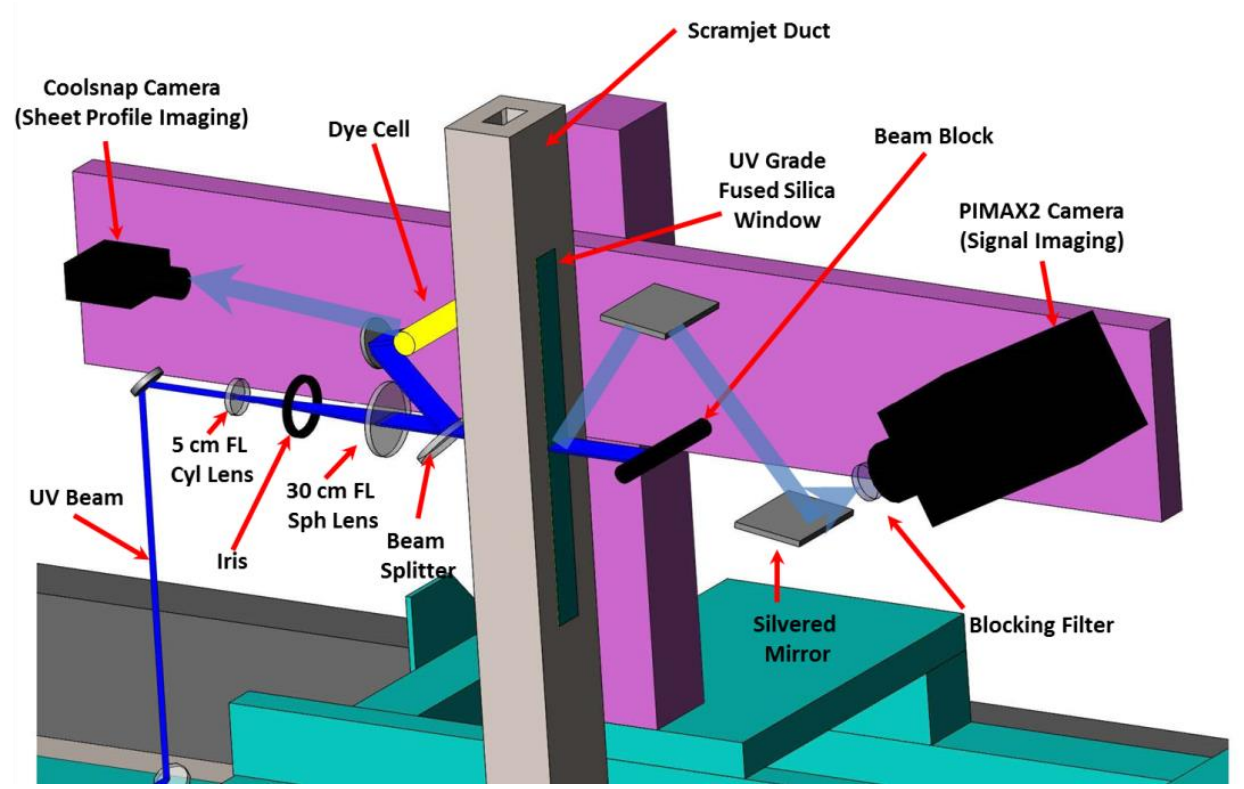

Figure 4. Schematic of optical setup cross-plane view of configuration 2 in the test room.

With respect to the cross-plane view $(y-z)$, the stream-wise view $(x-y)$ differed as follows. In order to fit the small periscope (made by a pair of $2.5 \times 5 \mathrm{~cm}$ silvered mirrors) on the observation side of the tunnel, the optical system was moved $15 \mathrm{~cm}$ away from the duct using the motorized translation stage. In addition, to maintain the same distance between the beam splitter-dye cell and the beam splitter-focusing plane, all the optics starting from the cylindrical lens and the dye cell were moved $16 \mathrm{~cm}$ toward the tunnel. A UV fused silica window was mounted on the "observation 
side" of the flow-path (the wall opposite the cavity) to allow the laser sheet to enter inside the duct parallel to the freestream. The stream-wise view allowed the PIMAX camera to be placed perpendicular to the laser sheet; hence, the Scheimpflug mount was not necessary, as shown in Figure 5.

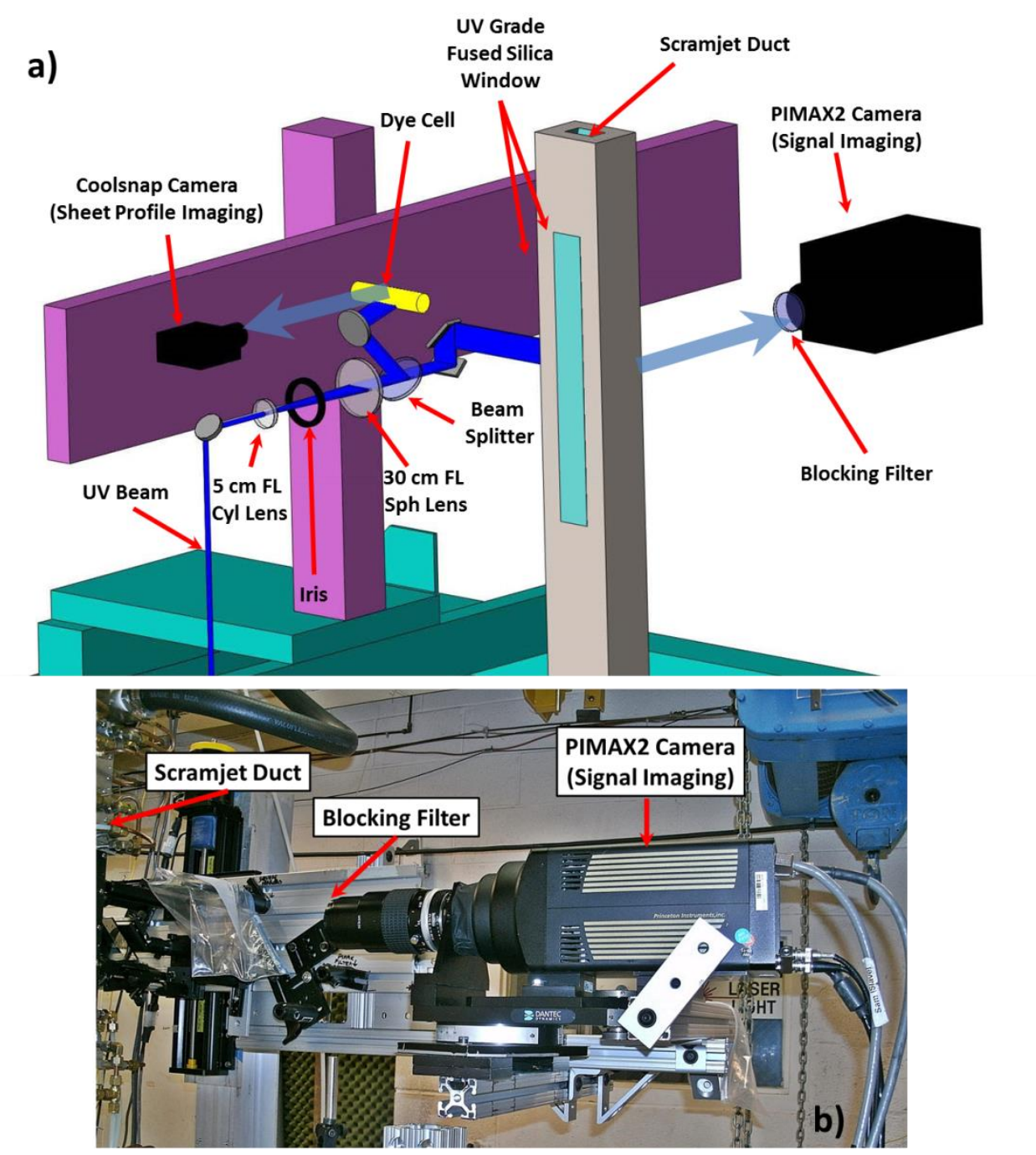

Figure 5. Optical setup stream-wise view in the test room; a) schematic; b) picture of the recording system after the scramjet duct. Plastic bags were removed during use.

\section{Data Processing}

A statistically significant number of images (500 single shots) were collected at $10 \mathrm{~Hz}$ for several injector configurations and equivalence ratios. All the recorded images were first background subtracted ${ }^{13}$ then processed to correct for geometrical distortion ${ }^{28}$ and laser intensity non-uniformities. The method used in the current work is nearly identical to the way it was performed and explained in Ref. 23. An example of the processing is shown in Figure 6. Images were rotated $180^{\circ}$ to match the coordinate system of previous work, cropped, and false colors added for a better visualization (Fig. 6b). An average was calculated from each sequence of images from a given run condition, as shown in Fig. 6c. 

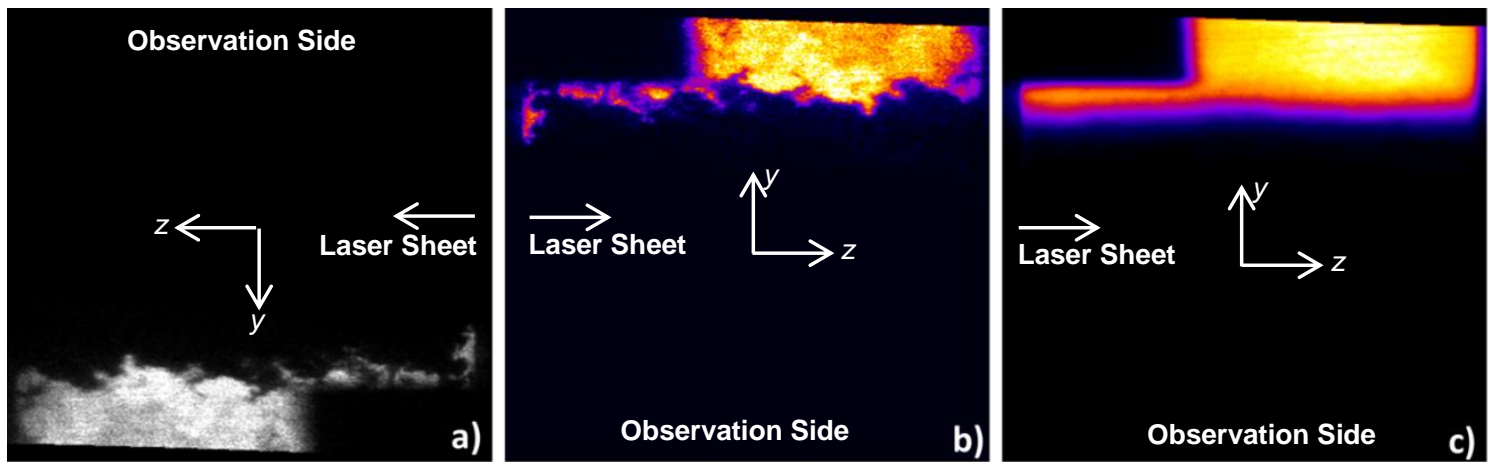

Figure 6. Final result of image processing $(\mathrm{ER}=0.44$, shock train $-45 x / H$, cross-plane view configuration 1$)$ : a) PLIF single-shot image corrected for distortion and laser intensity non-uniformities; b) PLIF image rotated $180^{\circ}$ and false color added; c) averaged over the full set of 500 images.

Intermittency ${ }^{29,30}$ is defined as the fraction of time that a significant amount of $\mathrm{OH}$ is present at a point in the flame. Images of intermittency were calculated: a threshold that was $20 \%$ of the peak value was applied to each single shot of a sequence of images to force each pixel to be either black or white, as shown on Figure 7a. White indicates the presence of combustion products (for $\mathrm{OH}$ ) or the presence of NO (for NO PLIF) while black indicates its absence. Then the stack of images was averaged resulting in an image with different gray scales (Fig. 7b) representing the intermittency. Finally another threshold function was applied leaving only the intermittency of 5\% indicating the flame limits (Fig. 7c). The same method was applied for both cross-plane view and stream-wise view (not shown in Fig. 7). These values were arbitrarily chosen but the same thresholds can be applied to CFD simulations for comparison. In Section III-B, both $5 \%$ and $95 \%$ intermittency lines will be obtained, marking the outer and inner edge of the intermittent region, where $\mathrm{OH}$ (or $\mathrm{NO}$ ) is intermittently present.

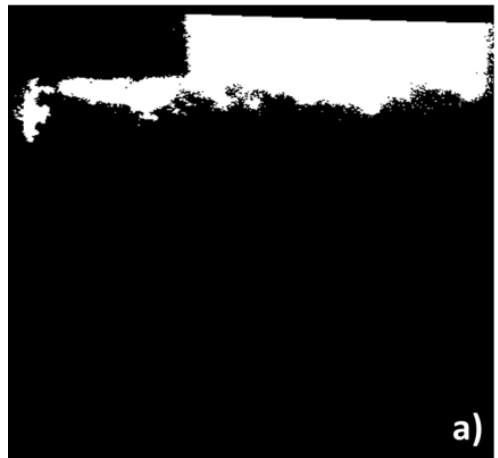

Figure 7. Intermittency processing: a) $20 \%$ thresholded single shot; b) average of a sequence of thresholded single shots; c) $5 \%$ intermittency

\section{A. Cross-Plane View}

All the tested cases are reported in Table 1. The fuel was always injected symmetrically with approximately half of the total fuel injected through the cavity-side injectors and half through the observation-side injectors. PLIF configurations 1 and 2 were both performed at multiple planes to produce a complete series of cross-plane views of the flame. For the base case, combustion alone generated enough backpressure to drive the shock train to the forward end of the isolator at $x / H=-45$. Therefore, the air throttle mechanism was not used to test in that case (Runs 4 and 9) with conditions dictated by previous mixing experiment. ${ }^{23}$ 


\begin{tabular}{cccccc}
\hline \hline Run & View & ER & $\begin{array}{c}\text { Shock Train } \\
(\mathrm{x} / \mathrm{H})\end{array}$ & Air Throttle & $\mathrm{T}_{0}[\mathrm{~K}]$ \\
\hline 1 & 1 & 0.26 & -45 & on & 1200 \\
2 & 1 & 0.31 & -45 & on & 1200 \\
3 & 1 & 0.31 & -15 & off & 1200 \\
4 & 1 & 0.42 & -45 & off & 1200 \\
5 & 1 & 0.42 & -45 & on & 1100 \\
6 & 2 & 0.26 & -45 & on & 1200 \\
7 & 2 & 0.31 & -45 & on & 1200 \\
8 & 2 & 0.31 & -15 & off & 1200 \\
9 & 2 & 0.42 & -45 & off & 1200 \\
10 & 2 & 0.42 & -45 & on & 1100 \\
\hline \hline
\end{tabular}

Table 1. Summary of tested conditions for OH PLIF cross-plane view.

The limits of operability of the flow-path have been determined in other work. ${ }^{20}$ The upper ER was 0.45 as mentioned in Ref. 20, while the lower ER limit of 0.3 was found by decreasing the ER until combustion was no longer sustained. The same approach was used to determine the blowout limit by lowering the total temperature. Further tests were performed using the air throttle to force the shock train location to always be at $x / H=-45$. This latter approach allowed for sustained combustion down to $E R=0.26$. For all the conditions reported in Table 1 the flame was stable and anchored on the cavity.

Figures 8 and 9 show a selection of single shots (top), average (middle) and standard deviation (bottom) for the base case recorded in both configuration 1 (Run 4) and 2 (Run 9) for all the tested planes. Each row of images has its own relative color scale to maximize the contrast and provide a better visualization; however the scale was maintained the same through the different planes in order to show the correct progression of the $\mathrm{OH}$ concentration at different locations. The single shot images show the flame propagation inside the combustor: the flame formed inside the cavity, where mixing of the combustion products and intermediates occurred, and then grew moving downstream. The single shot images also provide an indication of the local length scales of turbulence near the reaction zone: well defined turbulent flow structures are visible in the combustion region; however the smallest visible size of these structures is limited by the image resolution. The average images confirm the flame propagation trend observed in the single shot images; they also provide a better visualization of the increase of the $\mathrm{OH}$ concentration due to an accumulation of $\mathrm{OH}$ as a result of reaction during its downstream convection. Looking at single-shot and average images at planes 0 (Fig. 9) and 1 on both Figures 8 and 9 it can be observed that the concentration of $\mathrm{OH}$ in the cavity is almost constant, indicating good mixing. The standard deviation is small inside the cavity and large where the shear layer interacts with the freestream, enhancing the turbulence and the rate of heat release. Except for plane 0, two bands are present in the standard deviation images: the inner band indicates a fuel rich zone while the outer (brighter) band indicates a fuel lean zone; in the latter region the flow is highly turbulent and the combustion intermittent. Again, moving downstream, the bands are less strongly marked, indicating an increase in mixing and more uniform combustion. Moreover, images from Figure 8 and 9 show that, despite some edge effects, the middle of 3/5 of the shear layer is nearly two-dimensional. This observation justifies a simplified two-dimensional combustion modeling strategy, which decreases the resources required to predict this type of flow. 
Plane:

Selected

Single Shot:

Average:
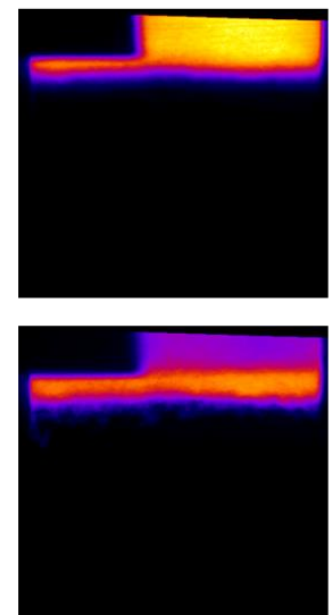

2
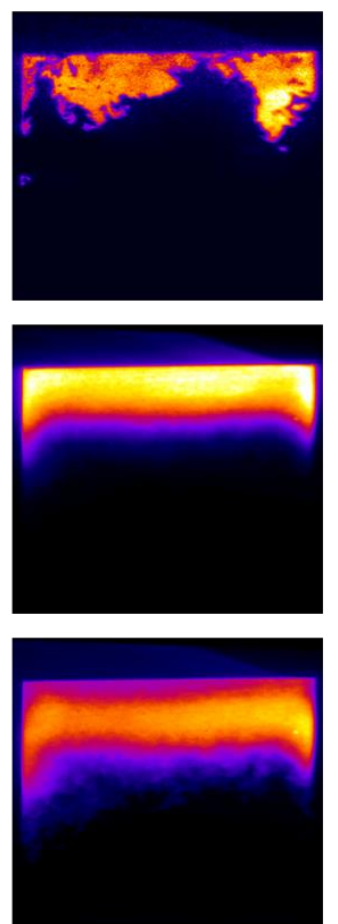

3
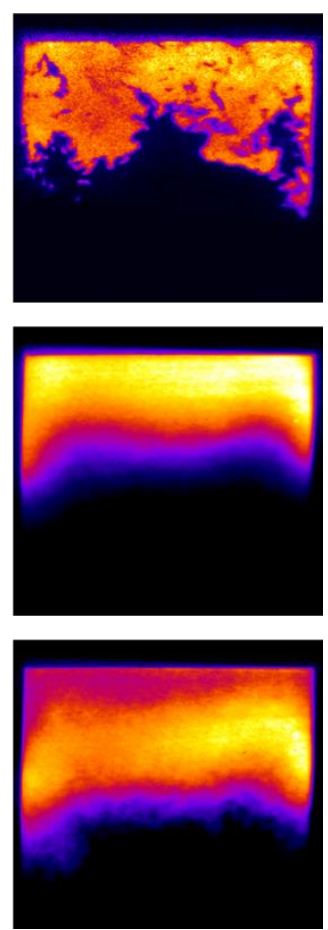

Figure 8 Base case, cross planes, configuration 1 (view from the bottom). Run 4 with ER $=0.42$ (injectors split equally) and shock train at $\mathrm{x} / \mathrm{H}=-45$, air throttle off, $\mathrm{T}_{0}=1200 \mathrm{~K}$.

Plane:

Selected

Single Shot:
0
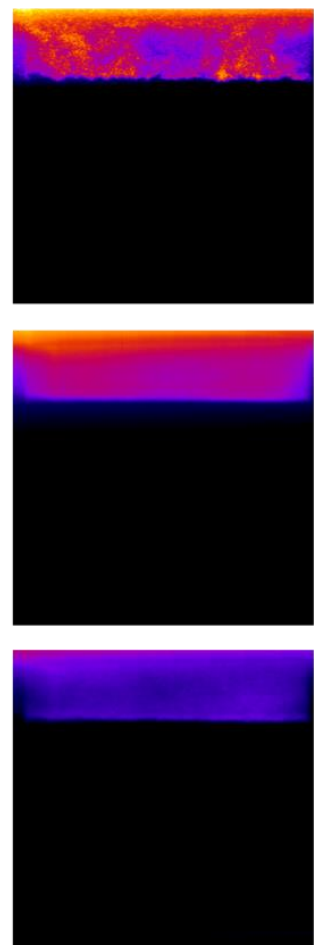

1
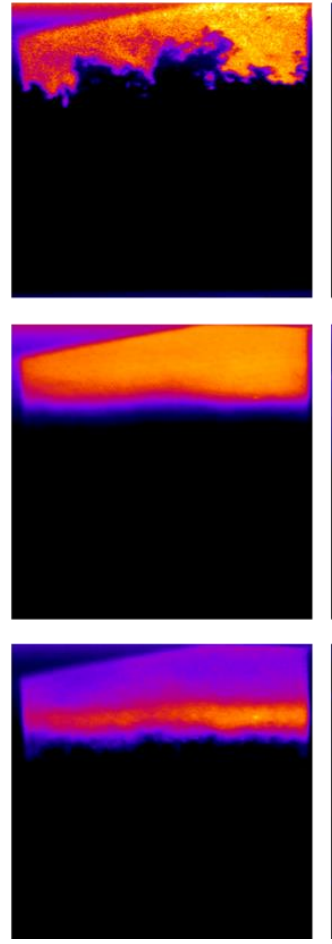

2
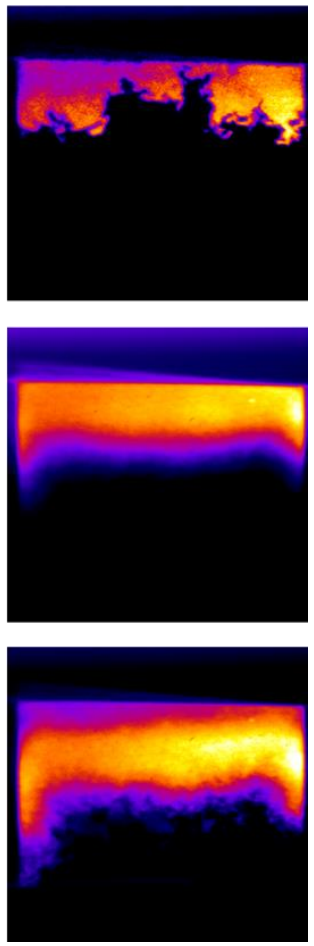

Figure 9 Base case, cross planes, configuration 2 (view from the top). Run 9 with $\mathrm{ER}=0.42$ (injectors split equally) and shock train at $x / H=-45$, air throttle off, $T_{0}=1200 \mathrm{~K}$. 
Figure 10 compares average images (configuration 1 view) between the base case and the cases recorded close to the flameout limits. Arbitrary but equivalent brightness and contrast setting are applied to each plane for a fair comparison between the different cases; however the color scale is was varied between different measurement locations.

Plane:
Run 4
(Base Case)

Run 1

(Low ER)
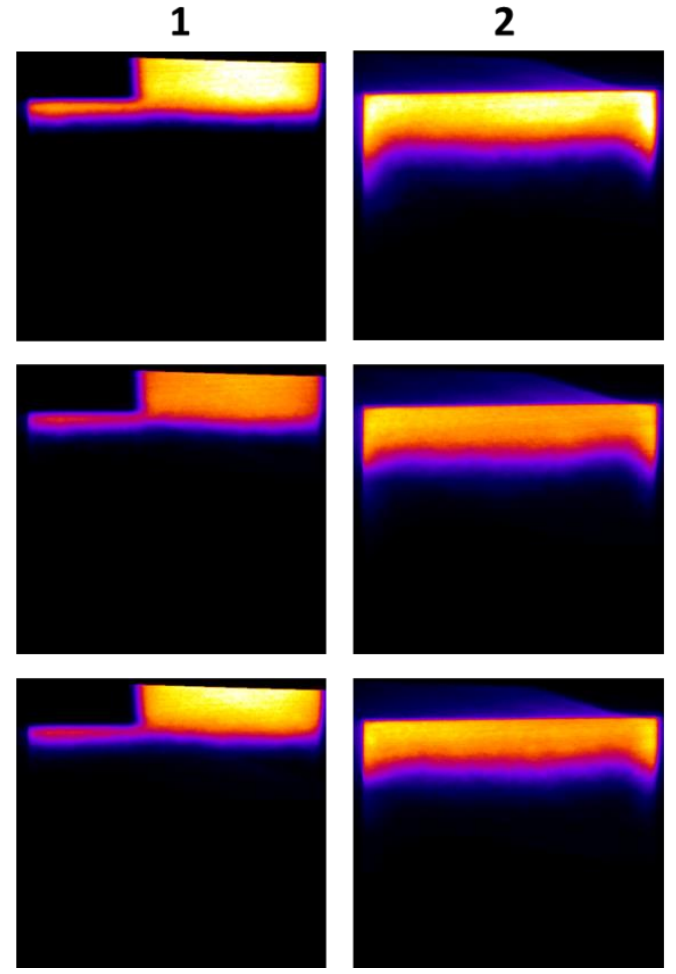

3
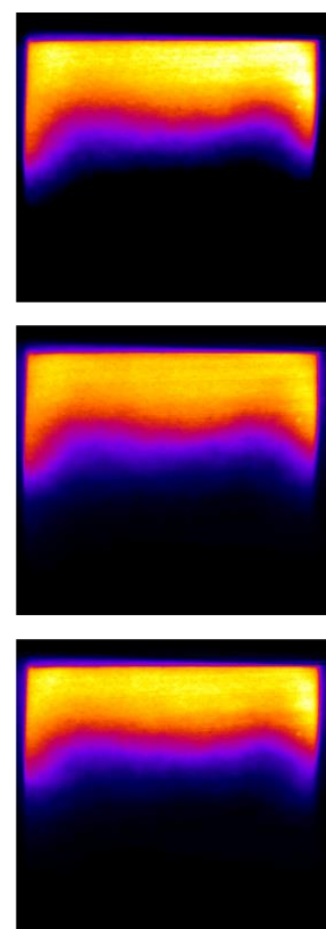

Figure 10. Cross-plane images for Base case (Run 4, ER=0.42, shock train at $\mathrm{x} / \mathrm{H}=-45$, air throttle off, $\mathrm{T}_{0}=$ $1200 \mathrm{~K}$, top) compared with low ER flameout limit (Run $1 \mathrm{ER}=0.26$, shock train at $\mathrm{x} / \mathrm{H}=-45$, air throttle on, $\mathrm{T}_{0}$ $=1200 \mathrm{~K}$, middle $)$ and low $T_{0}$ flameout limit $\left(\right.$ Run $5 \mathrm{ER}=0.42$, shock train at $\mathrm{x} / \mathrm{H}=-45$, air throttle on, $\mathrm{T}_{0}=$ $1100 \mathrm{~K}$, bottom).

A region of the average images in the center third of the duct between the cavity wall and the shear layer of the flame was averaged, and these average intensity values are plotted in Figure 11. From plane 1 to plane 3 the base case increases both in signal strength and in flame height indicating flame growth and propagation downstream. A lower ER (Run 1) results in more diluted combustion products and lower product temperature, and consequently lower $\mathrm{OH}$ signal than the base case (Run 4). A lower $\mathrm{T}_{0}$ (Run 5) implies a lack of heat available to initiate the combustion process; hence, the chemical kinetics are slower causing a delay in $\mathrm{OH}$ intensity build up. However, during all the tested runs, despite some cases being near the flameout limit, the flame was stably anchored on the cavity and highly repeatable. This fact provided information about the flow-path operability: combustion at the base case is robust for this geometry since a perturbation in ER or a change in $\mathrm{T}_{0}$ does not dramatically affect the combustion performance. 


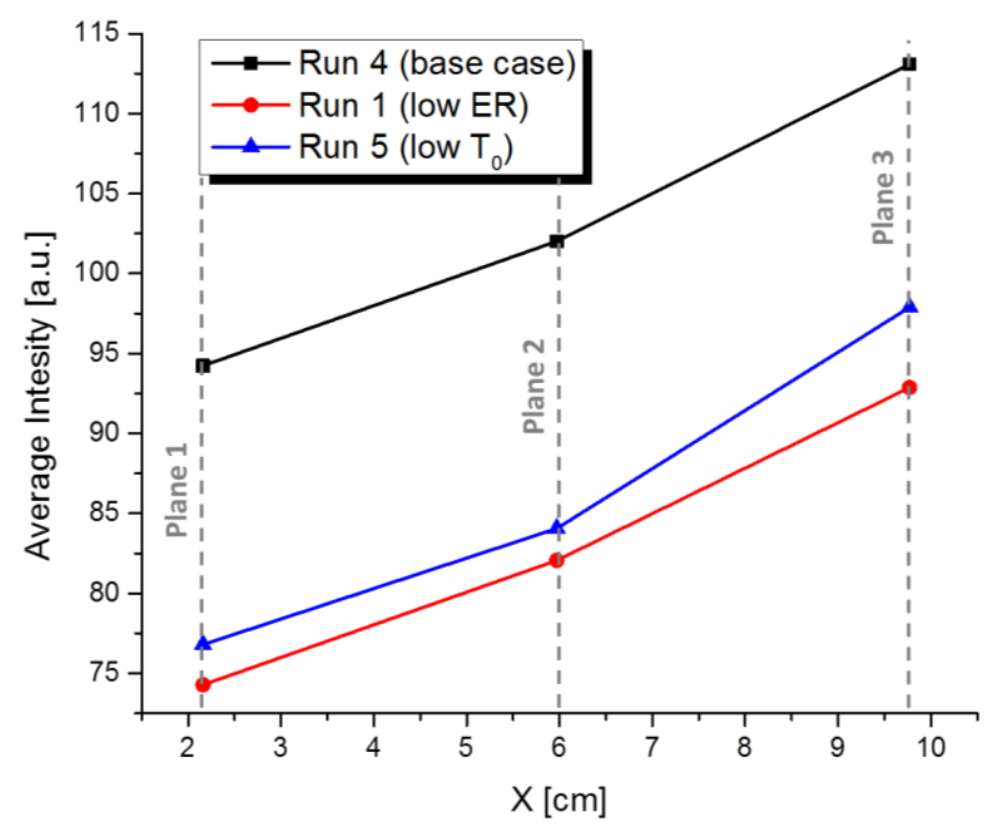

Figure 11. Average intensity (in arbitrary units) as the $\mathrm{OH}$ moved downstream (through planes 1, 2 and 3). Base case (Run 4, $\mathrm{ER}=0.42$, shock train at $\mathrm{x} / \mathrm{H}=-45$, air throttle off, $\mathrm{T}_{0}=1200 \mathrm{~K}$, top) compared with low ER flameout limit (Run 1, ER $=0.26$, shock train at $\mathrm{x} / \mathrm{H}=-45$, air throttle on, $\mathrm{T}_{0}=1200 \mathrm{~K}$, middle) and low $\mathrm{T}_{0}$ flameout limit (Run 5, ER $=0.42$, shock train at $\mathrm{x} / \mathrm{H}=-45$, air throttle on, $\mathrm{T}_{0}=1100 \mathrm{~K}$, bottom).

Figure 12 compares the average OH PLIF signal base case with the average temperature distribution obtained with the WIDECARS technique at the same conditions. The WIDECARS measurements were collected and analyzed by Gallo et al. ${ }^{16}$ Arbitrary color scales are applied to the OH PLIF images to maximize the image features; the same method is applied for WIDECARS images and a legend reporting the quantified temperature values is shown. Finally, the OH PLIF images were cropped and scaled to match the same view of the CARS data. Though the PLIF signal was not quantitative, the maximum $\mathrm{OH}$ concentration is expected to coincide (with a slight shift) with the maximum temperature according to Li et al. ${ }^{31}$ and Leung et al. ${ }^{32}$ This behavior is confirmed in Fig. 12: comparing OH PLIF and WIDECARS images, higher temperatures coincide with higher $\mathrm{OH}$ concentration. Also visible is a left-to-right flame asymmetry in all the images; this feature is more pronounced as the flame develops (plane 2 and plane 3 ). This effect was not caused by optical density an effect. Absorption of the laser sheet (as happened with the NO PLIF experiment) may perhaps have attenuated the laser intensity as it penetrated into the flow resulting in an asymmetric image; however, this optical phenomenon does not affect the CARS signal since information is determined from shape of spectrum not signal intensity, hence the asymmetry is real. This asymmetry is consistent with CFD calculation ${ }^{33,34}$ of the nozzle, inlet isolator and combustor with non-uniform-temperature inflow conditions based on CARS measurements; these calculations showed similar non-uniformities in predicted $\mathrm{OH}$ distribution to those that were measured. 
Plane:

1

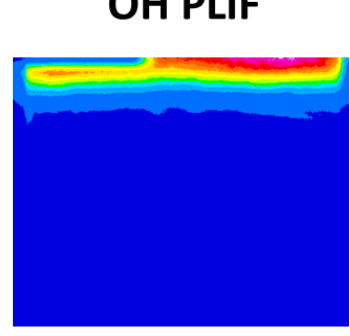

2

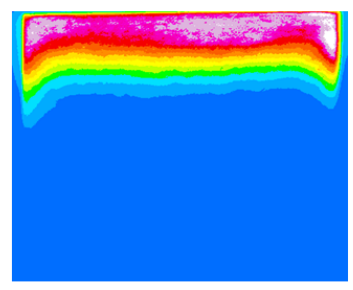

3

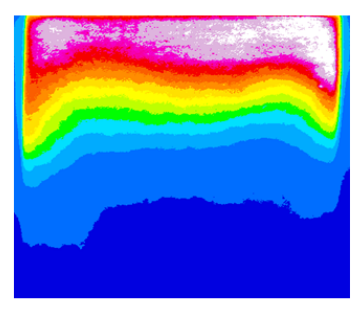

WIDECARS
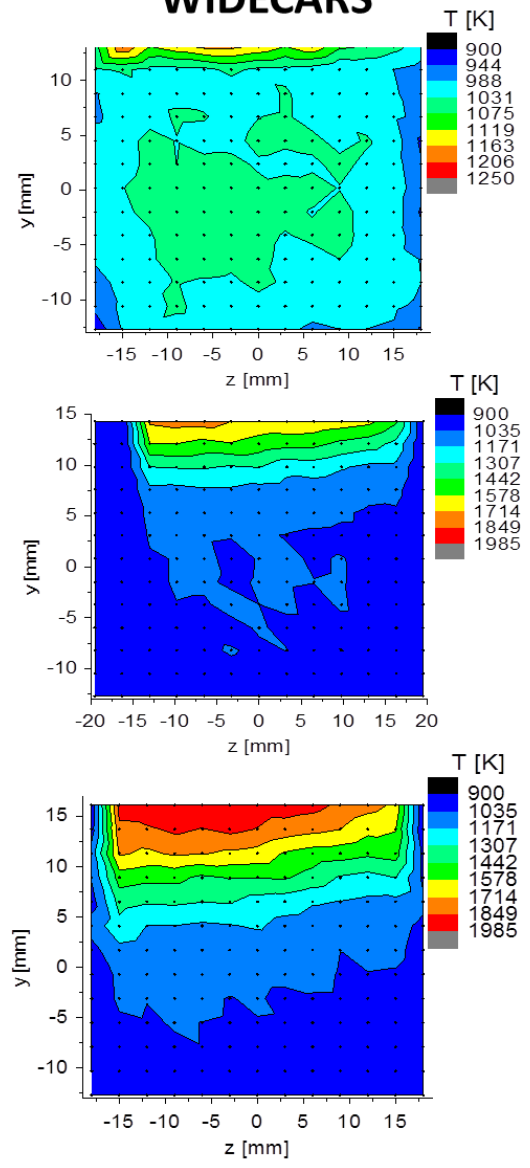

Figure 12. Base case $\left(E R=0.42\right.$, shock train at $\mathrm{x} / \mathrm{H}=-45$, air throttle off, $\left.\mathrm{T}_{0}=1200 \mathrm{~K}\right)$ comparison between average $\mathrm{OH}$ intensity (obtained with PLIF, configuration 1 view) and average temperature distribution (obtained with WIDECARS) for plane 1, 2 and 3.

\section{B. Stream-Wise View}

The stream-wise view text matrix, reported in Table 2, followed the same conditions as for the cross-plane view (Table 1). The air throttle was again used in some cases to force the shock train leading edge to $x / H=-45$. This approach enabled more straight forward comparisons of the results as only one parameter was varying at a time, for example ER or $\mathrm{T}_{0}$, while maintaining the same fuel mixing and freestream turbulence. As before, stable conditions close to the flame out limits were chosen for investigation.

\begin{tabular}{ccccc}
\hline \hline Run & ER & $\begin{array}{c}\text { Shock Train } \\
(x / H)\end{array}$ & Air Throttle & $\mathrm{T}_{0}[\mathrm{~K}]$ \\
\hline 1 & 0.26 & -45 & on & 1200 \\
2 & 0.31 & -45 & on & 1200 \\
3 & 0.31 & -15 & off & 1200 \\
4 & 0.42 & -45 & off & 1200 \\
5 & 0.42 & -45 & on & 1100 \\
\hline \hline
\end{tabular}

Table 2. Summary of tested conditions for OH PLIF stream-wise view. 
The stream-wise views were again acquired with sets of 500 single shot images. These data illustrate the streamwise flame formations and enable the calculation of a flame angle.

Figure 13 represents a selection of OH PLIF selected single shots (top) of the base case (Run 4) compared with the corresponding OH LES/RANS CDF simulation performed by Ramesh et al. ${ }^{34}$ The CFD image color scale was modified to match the PLIF images. As previously stated, it was not possible to record one single image to cover the entire combustor length, so the complete stream-wise view was obtained by combining 3 images which were recorded at different times. However, the single shot images show how the turbulent structures developed as the flame moved downstream: from small vortices during the flame formation upstream to a strongly wrinkled flame front due to large scale turbulence as the flame grew inside the divergent section. There is similarity with the CFD simulation in the overall extent of the flame propagation while smaller, sharper eddy structures are observed in the OH PLIF images.

OH PLIF Selected Single Shots

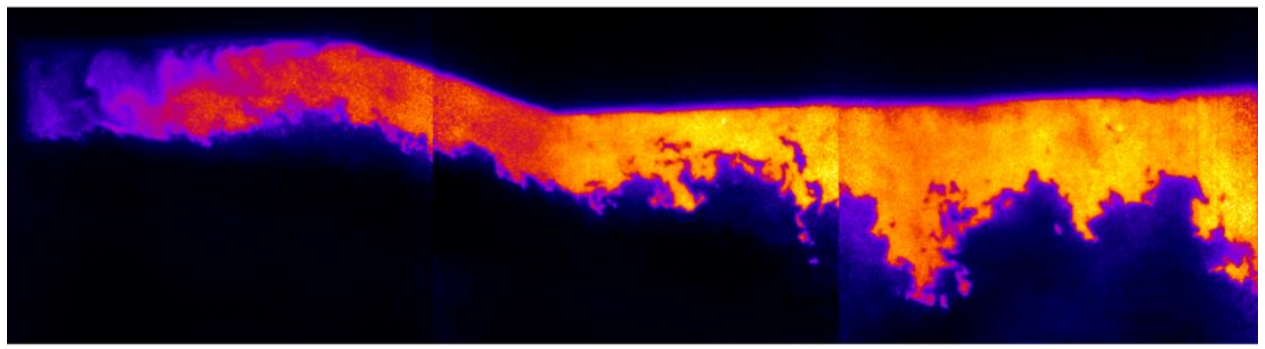

LES/RANS CFD

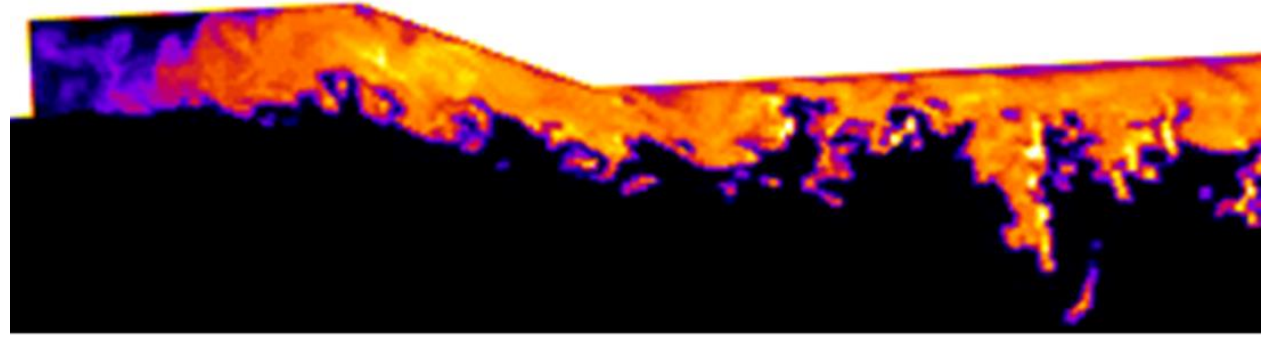

Figure 13 Comparison OH PLIF single shot images with LES/RANS CFD ${ }^{34}$ of the base case (Run 4) with ER $=0.42$ (injectors split equally) and shock train at $\mathrm{x} / \mathrm{H}=-45$, air throttle off, $\mathrm{T}_{0}=1200 \mathrm{~K}$.

Furthermore, in the cavity region, the CFD simulation predicts lower levels of $\mathrm{OH}$ than is indicated by the $\mathrm{OH}$ PLIF intensity. This would indicate a higher heat release and a higher speed of the reaction rate in the experiment compared to the CFD. However, this discrepancy could be caused by the $\mathrm{OH}$ not being a strictly quantitative measurement. Temperature, quenching or absorption effects could be affecting the PLIF intensity, so one should be cautious while interpreting OH PLIF intensities in this experiment.

The single shot images seem to suggest the presence of flame oscillations, as shown in Figure 14. Consecutive images are taken at $10 \mathrm{~Hz}$ which is a much lower frequency than frequencies associated with any unsteadiness in this flow; consequently images are uncorrelated. However, images in which structures are closest to the bottom wall are placed in the first and third rows while images with structures farthest from the bottom wall are placed in the second and fourth rows. This representation suggests a repeatable flame oscillation. LES/RANS simulations ${ }^{34}$ predicted $^{2}$ thermo-acoustic oscillations that created similar flame motions, as shown in Figure 15. The frequency of the oscillation was calculated at about $350 \mathrm{~Hz}$ in the CFD. Another study, performed by Ma, ${ }^{35}$ found the same oscillation frequency $(\sim 350 \mathrm{~Hz})$ for a similar geometry, fuel and ER $(0.40)$, but with different injection location (just before the cavity step). Fluctuations can be induced by periodic variations in the flow-field. Although the fuel consumption remains the decisive quantity, phase-dependent characteristics of the flow-field can trigger local changes in the fuel consumption rate: this is usually accompanied by significant cyclic variation in the flame shape and position. The main cause of this mechanism in computations was attributed to a thermo-acoustic wave which generated inside the combustor (acting as a resonator) coupling pressure oscillations and unsteady heat release. ${ }^{36}$ 


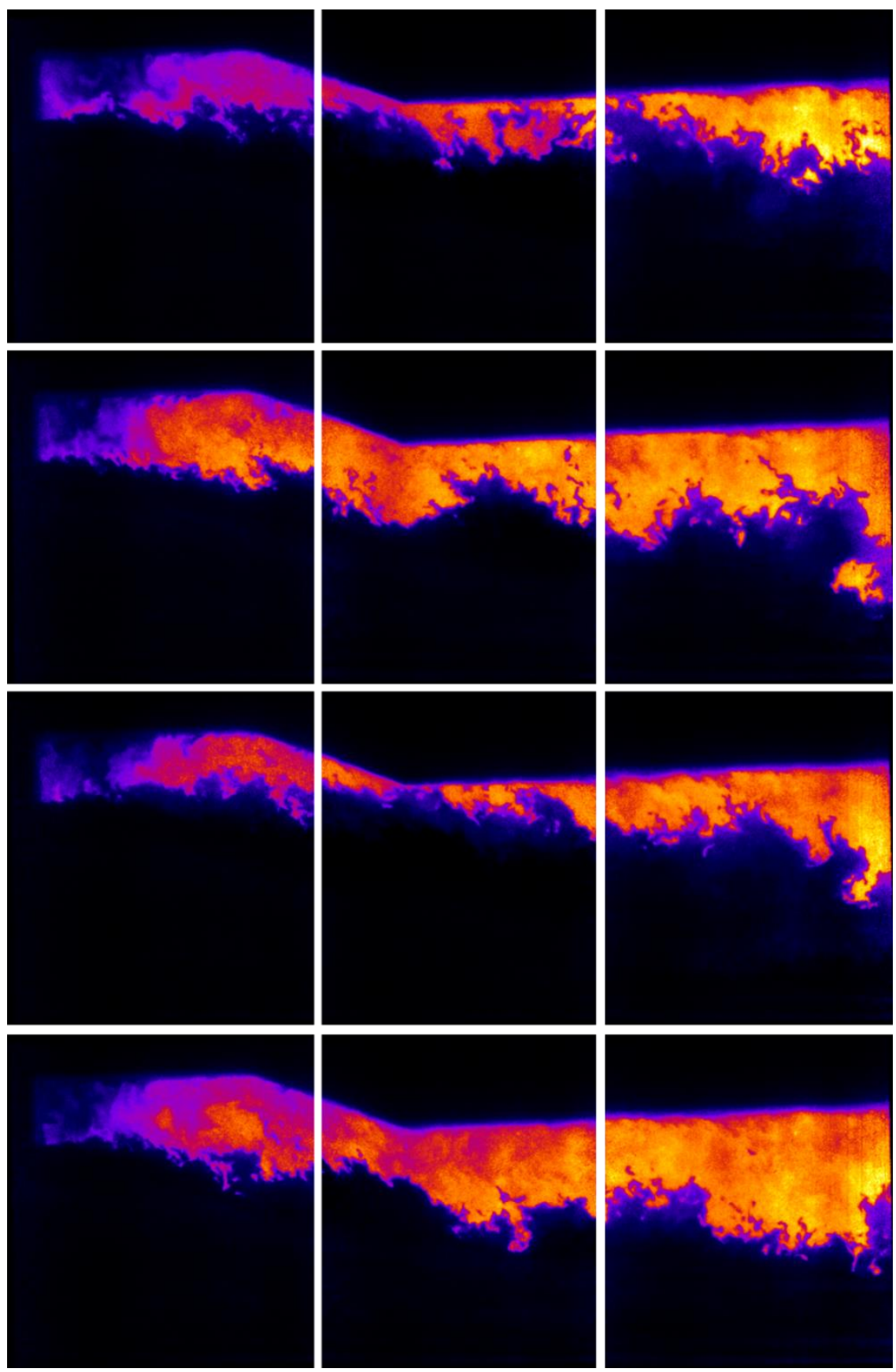

Figure 14. Flame oscillation inside the combustor. The vertical sequences represent the flame at different time steps where thermo-acoustic oscillations perturbed the combustion process. 

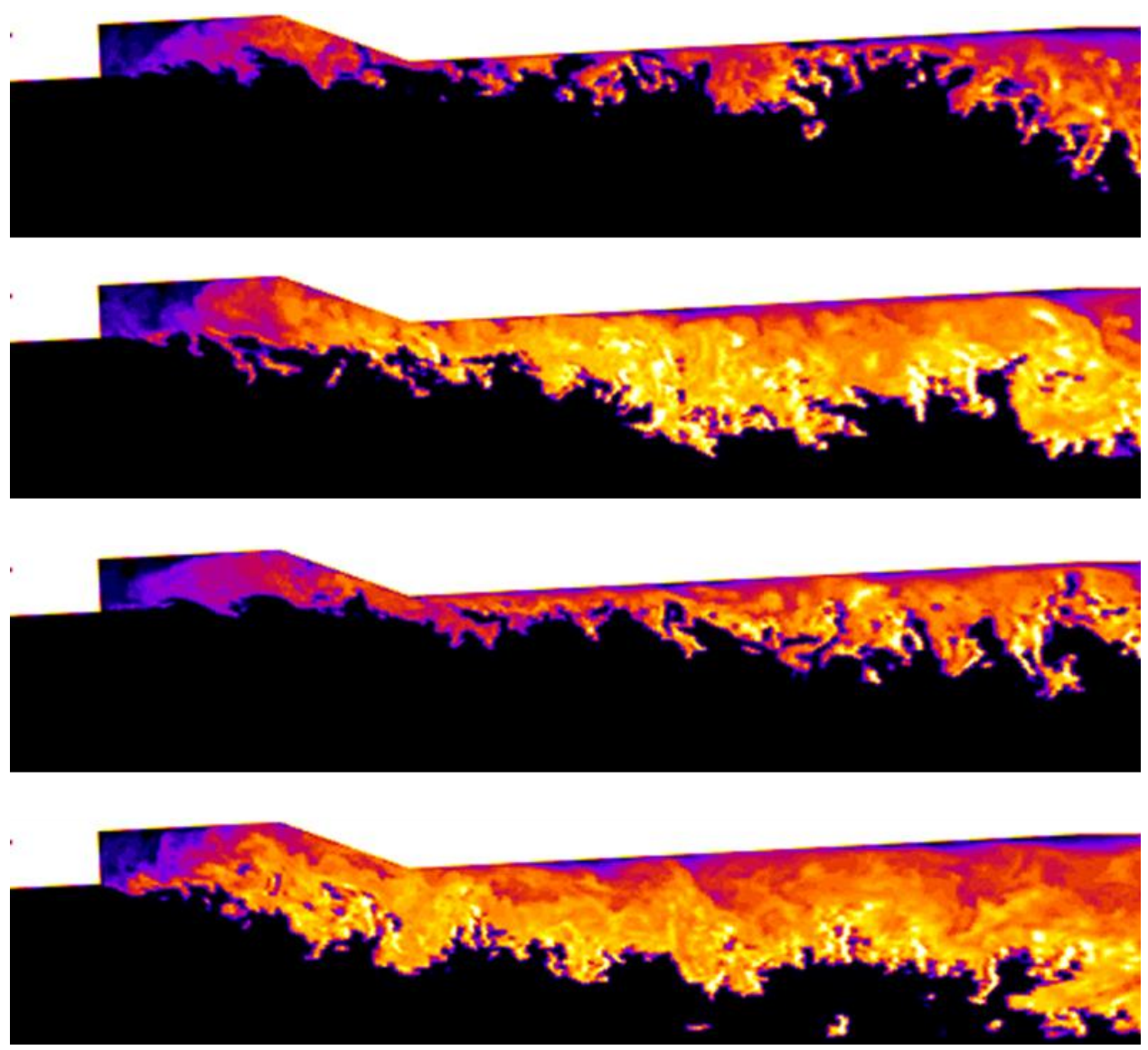

Figure 15. Flame oscillation inside the combustor predicted by LES/RANS simulations. ${ }^{34}$

A similar behavior was also observed previously during the NO PLIF experiment, ${ }^{23}$ shown in Figure 16. In this case the injection of a NO- $\mathrm{N}_{2}$ mixture $\left(10 \% \mathrm{NO}, 90 \% \mathrm{~N}_{2}, \mathrm{ER}=0.30\right)$ directly into the closeout ramp of the cavity; the goal was to study the mixing of gases between the cavity and freestream with cold runs. In addition, to keep the flowfield similar to the combustion case, pure $\mathrm{N}_{2}$ was equally $(\mathrm{ER}=0.42)$ injected from both observation and cavity side injectors and the shock train location was always forced to be at $x / H=-45$. From the images it can be inferred that oscillations were present inside the duct. However, it is not possible to claim periodicity from a random time set of images. It is also not possible to infer that the frequencies were similar since the PLIF images presented herein were acquired at $10 \mathrm{~Hz}$ and are therefore uncorrelated; however, even without heat release from combustion, the NO tracer simulated similar unsteadiness to combustion case. NO and OH PLIF images don't necessarily verify this oscillatory unsteadiness (because they are not time resolved) but they are consistent with it. This underlines the similarity between the non-combustion experiment and the combustion one. 

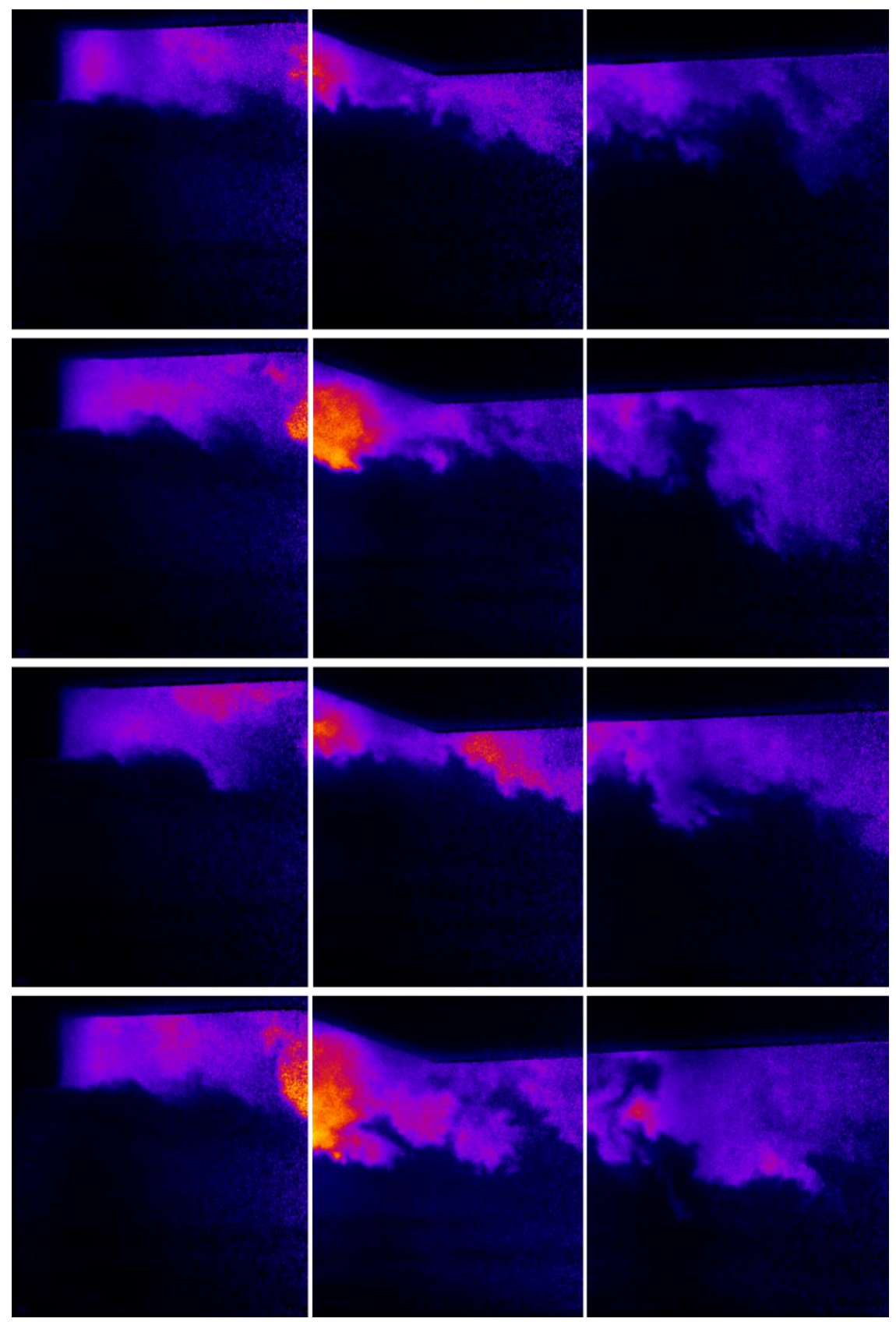

Figure 16. Single shots showing mixing of NO into the freestream. In the first and third row of images, NO is present close to the cavity wall; in the second and forth row of images NO spread more towards the centerline of the duct.

Figure 17 illustrates the average (top) and standard deviation (bottom) of the base case (Run 4). Inside the cavity the $\mathrm{OH}$ concentration was lower, indicating the temperature was lower because reaction was less complete here: this trend is also confirmed by WIDECARS measurements shown in Section V. 


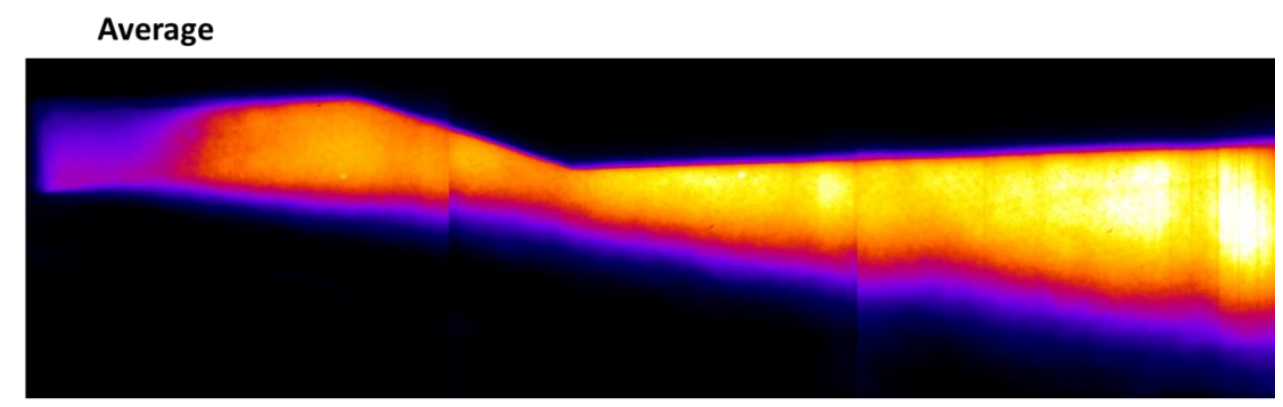

Standard Deviation

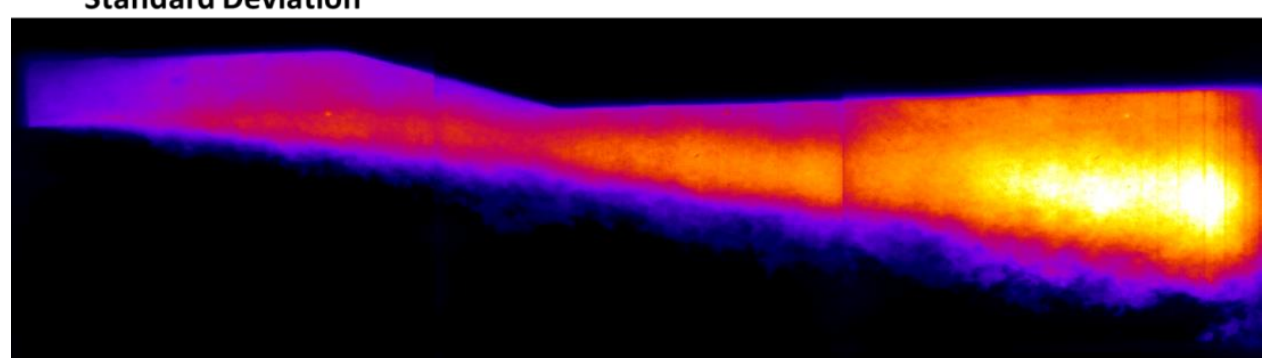

Figure 17. Average and standard deviation of the base case OH PLIF (Run 4) with ER = 0.42 (injectors split equally) and shock train at $x / H=-45$, air throttle off, $\mathrm{T}_{0}=1200 \mathrm{~K}$.

In the cavity, before reaching the ramp, chemical reactions occurred and the flame started to propagate: the orange zone in the middle of the cavity indicates at higher level of $\mathrm{OH}$, hence a higher temperature (as previously demonstrated with the comparison between cross-plane PLIF and WIDECARS). The temperature continued to rise moving downstream as demonstrated by an increase of $\mathrm{OH}$ : this feature confirmed the previous observations made in the cross-plane view (Fig. 8, 9 and 10). The standard deviation indicates less unsteadiness of OH into the cavity (constant purple zone), while higher values are found moving outside the cavity where the freestream interacted with the flame front increasing the turbulence and the rate of heat release, in agreement with the cross-plane view in Fig. 8 and 9.

Intermittency was derived from the stream-wise images and was used to image the flame limits. An arbitrary threshold of 5\% was applied to identify the outer flame limit while another threshold of $95 \%$ was used to establish the inner limit. Though these thresholds are arbitrary, the same thresholds can be used in computations for comparison. The region between these limits is the intermittent region of the flame. The intermittency limits of the base case are shown in Figure 18.

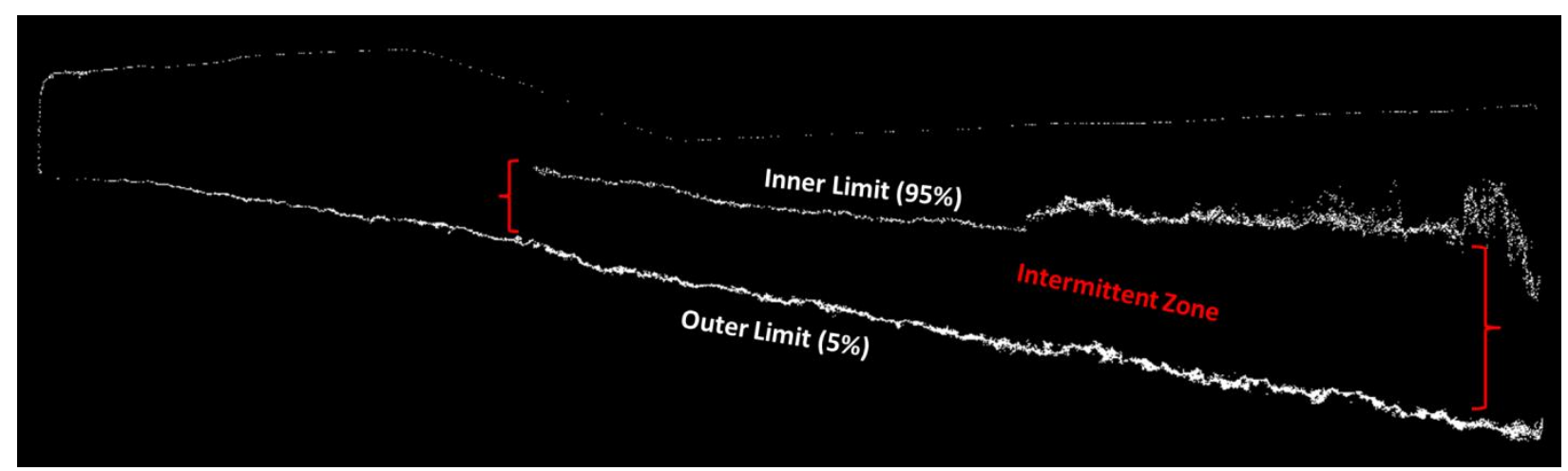

Figure 18. OH PLIF intermittency at $5 \%$ and $95 \%$ of the base case (Run 4) with ER = 0.42 (injectors split equally) and shock train at $\mathrm{x} / \mathrm{H}=-45$, air throttle off, $\mathrm{T}_{0}=1200 \mathrm{~K}$.

In a laminar flame the positive gradient of $\mathrm{OH}$ indicates a region of high heat release, and the presence of $\mathrm{OH}$ indicates that products are present (even if the combustion may not be fully completed). If $\mathrm{OH}$ is present in the flow 
more than $95 \%$ of the time the reaction was considered almost complete. Between the two limits there is the intermittent zone where regions of flow containing pure reactant are intermittently present, while at other times regions containing some amount of products; in the intermittent zone the degree of reaction progress may vary with time or be complete.

From the outer limit it was possible to define the average flame angle which can allow the different runs to be compared. Figure 19 shows lines of 5\% and 95\% intermittency for all the tested cases.

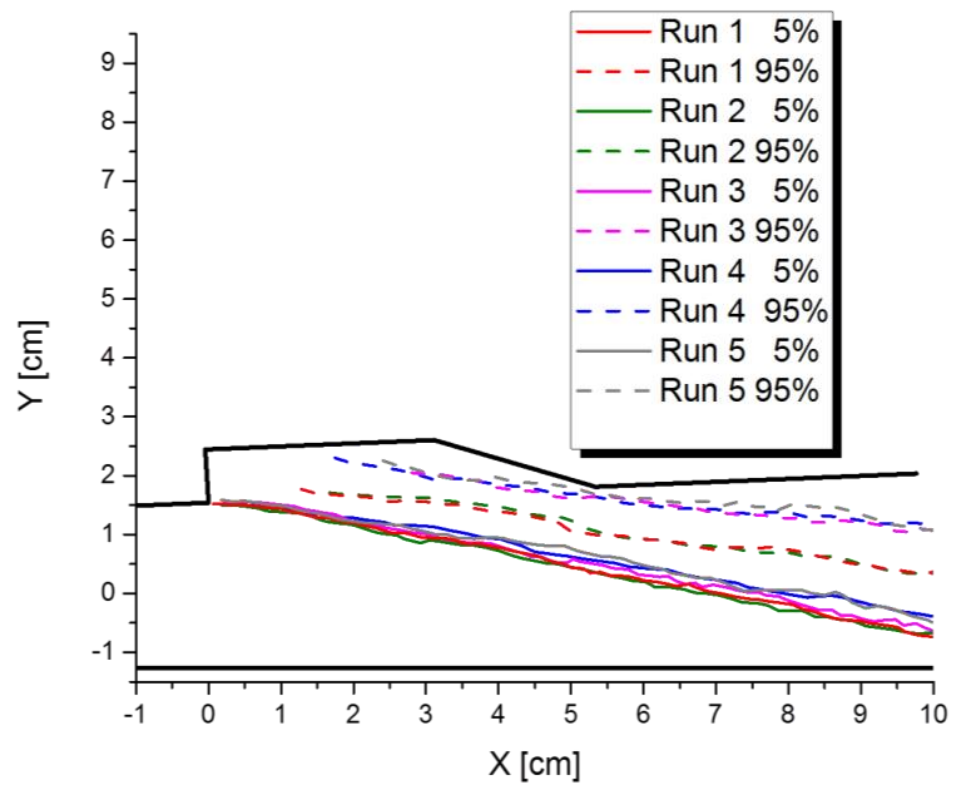

Figure 19. OH PLIF intermittency at 5\% (solid lines) and 95\% (dashed lines) for all the tested runs.

Note that the 95\% lines for Run $1(E R=0.26$, red dashed line) and $2(E R=0.31$, green dashed line) are farther from the wall. In these two runs the shock train was forced to be at $\mathrm{x} / \mathrm{H}=-45$ using the air-throttle mechanism to anchor the flame into the cavity, while for Run 3 ( $E R=0.31$, pink dashed line) the air throttle mechanism was off and the shock train leading edge was naturally measured at $\mathrm{x} / \mathrm{H}=-15$. The location of the shock may be connected with the displacement of the flame away from the cavity wall downstream of the cavity and better flame anchorage at the cavity. One possible explanation is that, when the shock is in the downstream location, the turbulence levels and velocity distribution entering the combustor are different than when at the upstream, perhaps leading to a reduced rate of turbulent mixing at the flame. Another possibility is that the location of the shock affects the frequency and amplitude of the thermo-acoustic oscillations. This could be because the oscillations are setup between two effective limits: on the upstream end the last shock waves in the isolator, on the downstream end the sonic throat (or the air throttle-mechanism location when it was in use). Fig. 14 and 15 have already shown that the oscillations are large leading to intermittency that extends close to the cavity wall. However, if the oscillation amplitudes were smaller due to a change in the upstream and downstream boundary conditions, then the width of the intermittent zone would be narrower, as observed in Run 3.

It can be noticed that for all the tested runs the flame front (5\% intermittency line) is almost coincident with only a small variation in the flame angle. Flame angle was calculated as the angle between a straight line (starting from the cavity step) drawn tangent to the 5\% intermittency line and the observation wall (x-axis). Table 3 shows the calculated flame angle for each case. 


\begin{tabular}{cccccc}
\hline \hline & Flame & \multicolumn{4}{c}{ Shock Train } \\
Run & Angle & ER & (x/H) & Air Throttle & $\mathrm{T}_{0}[\mathrm{~K}]$ \\
\hline 1 & $11.3^{\circ}$ & 0.26 & -45 & on & 1200 \\
2 & $10.9^{\circ}$ & 0.31 & -45 & on & 1200 \\
3 & $11.1^{\circ}$ & 0.31 & -15 & off & 1200 \\
4 & $10.4^{\circ}$ & 0.42 & -45 & off & 1200 \\
5 & $10.5^{\circ}$ & 0.42 & -45 & on & 1100 \\
\hline \hline
\end{tabular}

Table 3. Summary of the flame angle for all the tested cases based on $5 \%$ intermittency.

As expected from Figure 19, all the tested cases had a similar flame angle varying from $10.4^{\circ}$ (Run 4 ) to $11.3^{\circ}$ (Run 1) with the uncertainty of $\pm 0.3^{\circ}$.

The base case 5\% and 95\% intermittency lines were also compared with NO PLIF, WIDECARS ${ }^{16}$ and LES/RANS CFD. ${ }^{34}$ The WIDECARS intermittency was determined based on CARS temperature greater than $100 \mathrm{~K}$ above the freestream temperature. Intermittency for CFD was obtained from $\mathrm{OH}$ concentration results processed using the same method described in Section II-C. The results are shown in Figure 20. The inner limit (95\%) is very similar for all combustion cases. The NO PLIF non-combustion case shows a different behavior since the intermittency indicates the spread of NO into the cavity just after the injection. Comparing the $95 \%$ intermittency with the $5 \%$ one for combustion cases, it can be noticed a similar trend: OH PLIF shows the steeper angle, while WIDECARS the lowest one with the LES/RANS simulation in between the previous two.

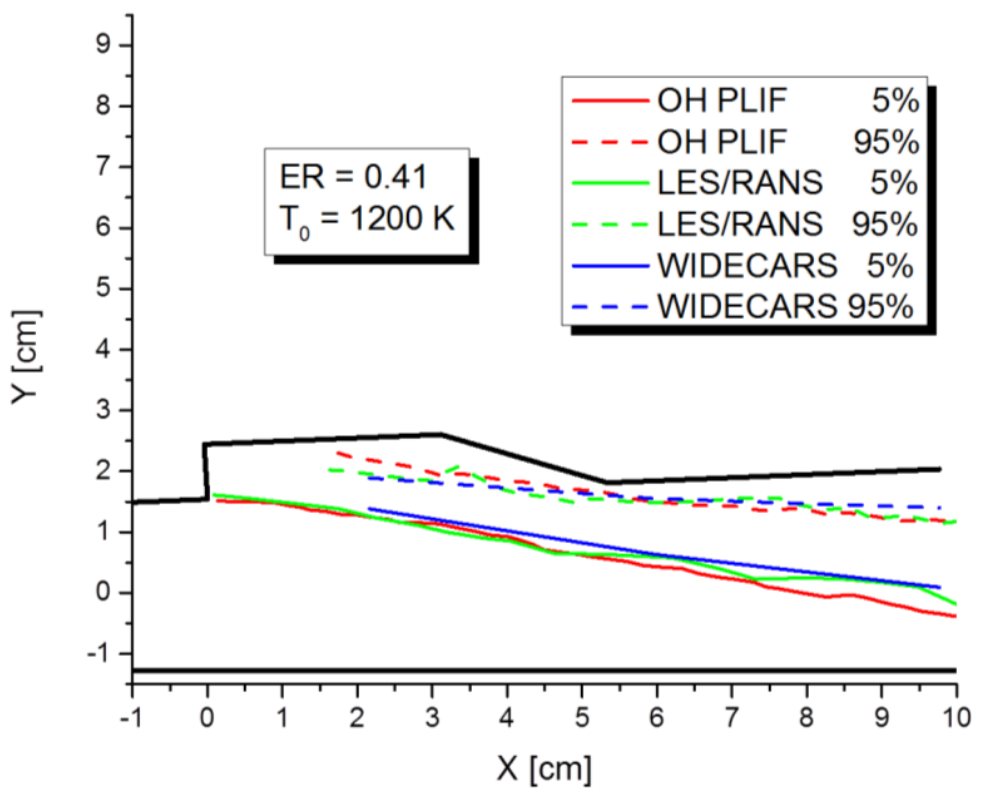

Figure 20. Average flame angle comparison for the base case between OH PLIF, LES/RANS CFD, and WIDECARS.

Good agreement was found among all the measurements of average flame angle, around $10^{\circ}$; a summary of all the average flame angle calculation for the base case is provided by Table 4 . 


\begin{tabular}{|c|c|c|c|c|c|}
\hline Technique & $\begin{array}{l}\text { Average } \\
\text { Flame Angle }\end{array}$ & ER & $\begin{array}{l}\text { Shock Train } \\
(\mathrm{x} / \mathrm{H})\end{array}$ & Air Throttle & $\mathrm{T}_{0}[\mathrm{~K}]$ \\
\hline OH PLIF & $10.4^{\circ}$ & 0.41 & -45 & off & 1200 \\
\hline LES/RANS & $10.2^{\circ}$ & 0.41 & -45 & off & 1200 \\
\hline WIDECARS & $9.6^{\circ}$ & 0.41 & -45 & off & 1200 \\
\hline
\end{tabular}

Table 4. Summary of the average flame angle with different measurement techniques for the base case only.

Though the WIDECARS result was limited to only 3 points since the CARS measurement were only performed for planes 1,2 and 3 cross-plane view, the average flame angle is very close to the experimental OH PLIF with less than $1^{\circ}$ of difference. Furthermore the method used to calculate the intermittency from WIDECARS was based on temperature and not OH PLIF intensity: although the threshold applied followed the same approach, the different quantity measured could have caused this discrepancy in flame angle calculation. LES/RANS predicted almost the same average angle of OH PLIF: just $0.2^{\circ}$ of difference which is within the uncertainty of the measurement. Although the numerical simulation was not able to capture all the small structures seen in the OH PLIF images, the overall behavior of the flame is well modeled and the simulation is in agreement with the experimental results.

The angle at which the NO propagates outwards is different for the lower flow rate of fuel simulant. In fact, the angle is determined both by diffusion of species and the increase in volume occupied by product gas compared to reactant (the volume occupied by a given number of moles of gas increases due to combustion through increase of temperature and the ideal gas law). Looking at Figure 21 it can be observed that runs with lower ER (green and blue lines) result in a very low volume occupied by the injected fuel simulant, which generated a very low diffusion angle ( $7.0^{\circ}$ and $8.2^{\circ}$ respectively). On the other hand, the higher ER (purple line) provided enough injected volume to push the freestream outwards to define a NO 5\% intermittency profile close to simulate a larger flame angle. Hence, Run 3 was considered close enough to the flame angle of the other cases and used for comparison. The difference between NO PLIF and OH PLIF average flame angle is less than $1^{\circ}$. This is because both methods mark the diffusion of species (NO PLIF marks the turbulent diffusion of species while OH PLIF the diffusion of combustion products) from the cavity and because the volume effect of heat release of combustion was simulated by the added volume of fuel simulant in the NO PLIF case.

This similarity between $\mathrm{NO}$ and $\mathrm{OH}$ was already noticed in the stream-wise single shots analysis. This implies that the flame propagated by the same mechanism that diffused the NO tracer. Clearly, the edge of NO distribution in the non-combustion experiment was propagated only by the freestream turbulence, since there was no other mechanism (e.g. heat release) for the NO to mix outwards. The propagation of the flame in this experiment, occurring as it does as a result of freestream turbulence, differs from the propagation of a turbulent flame in a premixed quiescent medium which occurs as a result of turbulence generated by instabilities that arise out of heat release and concentration gradients. Comparing the $\mathrm{NO}$ and $\mathrm{OH}$ experiments, the freestream turbulence appears to be the predominant effect that drives the flame (or the simulated flame) propagation. 


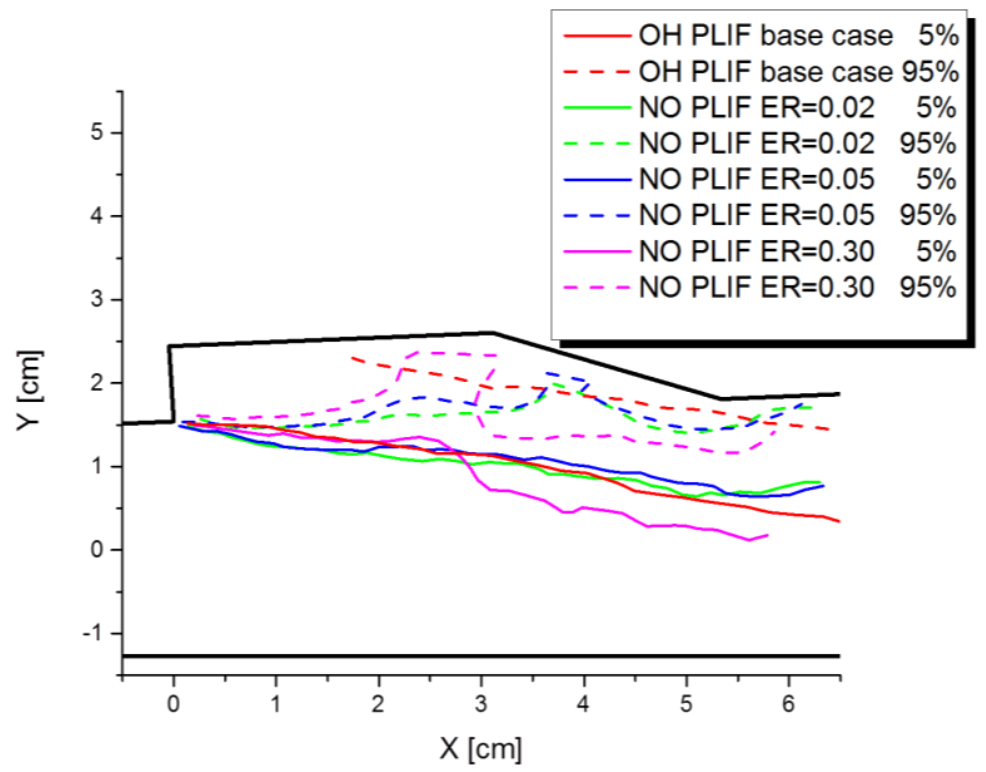

Figure 21. Comparison between combustion base case (OH PLIF) and non-combustion cases (NO PLIF).

\section{Conclusions}

OH PLIF images were acquired in an ethylene-fueled scramjet combustor at four different measurement planes,. The $\mathrm{OH} \mathrm{Q}_{1}(8)$ line was excited to provide a signal that is approximately linear with mole fraction and almost insensitive to temperature and pressure variation in the range of the measurements. Images were processed to remove background (i.e. room light, laser scattered light, etc.) and to correct for geometrical perspective, camera lens distortions, and laser non-uniformities. Several ERs were tested to replicate the base case (determined from a previous NO PLIF mixing experiment), and conditions close to the flameout limits of the combustor. A downstream air throttle was used in some cases to provide additional back pressure and move the isolator shock train forward in the duct. This allowed stable combustion at a lower ER and $\mathrm{T}_{0}$ than was possible without the air throttle.

Images were recorded both at cross-planes and stream-wise planes providing information about the flame development and structures: both views demonstrated the increase of $\mathrm{OH}$ production along the scramjet duct. Single shots gave qualitative information about how the turbulent eddies grow and their sizes and change of size. As expected, the flame formed inside the cavity and then grew in size moving downstream. Standard deviations confirmed what was observed in the single shot images: low values inside the cavity indicate nearly complete combustion, while higher values are present downstream as the flame grows.

A comparison of the base case with conditions close to the flameout limits was conducted. Despite being close to flameout, the flame was always stably anchored in the cavity and highly repeatable. Hence perturbations (in terms of ER or $\mathrm{T}_{0}$ ) around the base case do not significantly affect the flame propagation.

A comparison with WIDECARS temperature data was also performed, which found a good agreement at all measurements planes: higher concentration of $\mathrm{OH}$ corresponded to higher temperatures and vice versa. Asymmetry of the flame front was observed in both measurements indicating it is not due to laser radiative trapping but rather to non-uniformity nozzle inflow conditions: this statement is also confirmed by CFD simulations. Stream-wise view images were compared with RANS/LES simulations: single shots were in agreement regarding flame development downstream and vortex sizes. However, the CFD showed a different trend in the $\mathrm{OH}$ concentration inside the cavity: the relative $\mathrm{OH}$ concentration levels in the cavity are higher than in the flame further downstream. The flame was also found to oscillate inside the combustor as previously observed in the NO PLIF experiment. Although it was not possible to quantify experimentally the frequency of the oscillation due to a slow system acquisition rate, the 
visualization was consistent with a RANS/LES simulation, which predicts flame instabilities due to a thermo-acoustic standing wave at a frequency of $\sim 350 \mathrm{~Hz}$.

Intermittency was computed and the 5\% and the $95 \%$ intermittency lines were used to identify the flame front and the reacting zone limits. Two cases with same ER (0.30) but different shock train locations (leading edge at $x / H=-15$ $\mathrm{x} / \mathrm{H}$ and -45 respectively) showed different inner limit: the limit was closer to the cavity wall with the shock train located further downstream (at $x / H=-15$ ). A possible reason for this observation is a change in turbulence levels and velocity distribution generated due to a different location of the shock train length. Another plausible cause is that the location of the shock affected the frequency and amplitude of previously observed thermo-acoustic oscillations. In fact, if the oscillation amplitudes were smaller due to a change in the upstream (the shock waves in the isolator) and downstream (the sonic throat or the air throttle location) boundary conditions, then the width of the intermittent zone would be narrower, as observed when the shock train was at $x / H=-15$.

Flame angle was calculated from 5\% intermittency images, but only a slight variation was found for the tested cases: the flame angle varied from $10.3^{\circ}$ to $11.6^{\circ}$ (with uncertainty of $\pm 0.3^{\circ}$ ). A comparison of the base case with NO PLIF, WIDECARS and a RANS/LES simulation was also conducted. The flame angles determined from all of these techniques falls approximately $10^{\circ}$. Experimental OH PLIF and WIDECARS are in agreement with less than $1^{\circ}$ of difference while the CFD simulation is in agreement with a $0.2^{\circ}$ difference.

Finally a comparison between the OH PLIF flame angle and NO diffusion angle was performed. Lower NO concentrations (simulated ER $=0.02$ and 0.05 ) generated a lower diffusion angle while a higher concentration (simulated ER $=0.30)$ provided enough injected volume to push the freestream outwards to define a NO 5\% intermittency profile sufficient to simulate a flame angle. The angle calculated from the higher NO concentration differed by less than $1^{\circ}$ from the OH PLIF measurement. This reflects the similarity between NO and $\mathrm{OH}$ that was previously noted with respect to acoustic oscillations and implies that the flame in the $\mathrm{OH}$ experiment propagated according to the same mechanism that diffused the fuel simulant in the NO experiment. This similarity has an important implication in understanding how the flame propagates: the freestream turbulence is the predominant effect (over heat release and concentration gradients) that drives the flame propagation angle in this combustor.

\section{Acknowledgements}

This research was funded by the National Center for Hypersonic Combined Cycle Propulsion, grant no. FA-955009-1-0611, with Chiping Li (U.S. Air Force Office of Scientific Research), Aaron Auslender (NASA), and Rick Gaffney (NASA) serving as technical monitors. The authors are also thankful to Justin Kirk (University of Virginia) and Damien Lieber (University of Virginia) for their help in operating and monitoring the facility during the tests and Kiran Ramesh (North Carolina State University) and Jack Edwards (North Carolina State University) for providing LES/RANS data for comparison. Paul Danehy was supported by the NASA Fundamental Aeronautics Program. Craig Johansen was supported by the Natural Sciences and Engineering Research Council (NSERC) of Canada.

\section{References}

${ }^{1}$ A. C. Eckbreth, "Laser Diagnostics for Combustion Temperature and Species $2^{\text {nd }}$ Edition", Combustion Science \& Technology Book Series, Vol. 3, Taylor \& Francis , New York, 2002

${ }^{2}$ S. O'Byrne, “ Hypersonic Laminar Boundary Layers and Near-Wake Flows”, Ph.D. Thesis, The Australian National University, 2001

3 J.L. Palmer, B. K. McMillin, R. K. Hanson, "Planar Laser-Induced Fluorescence Imaging of Velocity and Temperature in Shock Tunnel Free Jet Flow", AIAA 92-0762, 30 th Aerospace Sciences Meeting and Exhibit, Reno, NV, 1992

${ }^{4}$ B.K. McMillin, J. L. Palmer, R. K. Hanson, "Temporally Resolved, Two-Line Fluorescence Imaging of NO Temperature in a Transverse Jet in a Supersonic Cross Flow", Applied Optics, Vol. 32, No. 36, 1993 
${ }^{5}$ F. G. Kidd III, V. Narayanaswamy, P. M. Danehy, J. A. Inman, B. F. Bathel, K. F. Campbell, N. E. Hass, D. P. Capriotti, T. g. Drozda, "Characterization of the NASA Langley Arc Heated Scramjet Test Facility Using NO PLIF", AIAA 2014-2652, $30^{\text {th }}$ AIAA Aerodynamic Measurements Technology and Ground Testing Conference, Atlanta, GA, 2014

${ }^{6}$ R. J. Hartfield, J. D. Abbitt, J. C. McDaniel. "Injectant mole-fraction imaging in compressible mixing flows using planar laser-induced iodine fluorescence", Optics letters, Vol. 14, No. 16, 1989, pp. 850-852

${ }^{7}$ J. M. Donohue, J. C. McDaniel, "Computer-controlled multiparameter flowfield measurements using planar laser-induced iodine fluorescence", AIAA Journal, Vol. 34, No. 8, 1996, pp. 1604-1611

${ }^{8}$ H. Takahashi, S. Ikegami, H. Oso, G. Masuya, M. Hirota, "Quantitative Imaging of Injectant Mole Fraction and Density in a Supersonic Mixing", AIAA Journal, Vol. 46, No. 11, 2008, pp. 2935-2943.

${ }^{9}$ C. C. Rasmussen, S. K. Dhanka, J. F. Driscoll, "Visualization o Flameholding Mechanism in a Supersonic Combustor Using PLIF", Proceeding of the Combustion Institute, Vol. 31, 2007, pp. 2505-2512

${ }^{10}$ J. M. Donbar, M. R. Gruber, T. A. Jackson, C. D. Carter, T. Mathur, "OH Planar Laser-Induced Fluorescence in a Hydrocarbon-Fueled Scramjet Combustor", Proceeding of the Combustion Institute, Vol. 28, 2000, pp. 679-687

${ }^{11}$ M. J. Gaston, A. F. P. Houwing, N. R. Mudford, P. M. Danehy, J. S. Fox, "Fluorescence imaging of mixing flowfields and comparisons with computational fluid dynamic simulations", Shock Waves, Vol. 12, No. 2, 2002 , pp. 99-110

${ }^{12}$ M. R. Gruber, J. M. Donbar, C. D. Carter, K. Y. Hsu, "Mixing and Combustion Studies Using Cavity-Based Flameholder in a Supersonic Flow”, Journal of Propulsion and Power, Vol. 20, No. 5, 2004, pp. 769-783

${ }^{13}$ C. T. Johansen, C. D. McRae, P. M. Danehy, E. C. A. Gallo, L. M. L. Cantu, G. Magnotti, A. D. Cutler, “OH PLIF Visualization of the UVa Supersonic Combustion Experiment: Configuration A", Journal of Visualization, Vol. 17, No. 2, 2014, pp. 131-141

${ }^{14}$ C. D. McRae, C. T. Johansen, P. M. Danehy, E. C. A. Gallo, L. M. L. Cantu, G. Magnotti, A. D. Cutler, R. D. Rockwell, C. P. Goyne, J. C. McDaniel, "OH PLIF Visualization of the UVa Supersonic Combustion Experiment: Configuration C”, AIAA 2013-0034, 51 ${ }^{\text {st }}$ AIAA Aerospace Meeting, Grapeville, TX, 2013

15 J. W. Kirk, R. F. Johnson, C. P. Goyne, H. K. Chelliah, J. C. McDaniel, R. D. Rockwell, "Velocimetry Using Graphite Tracer Particles in a Scramjet Flowpath", AIAA 2015-0355, 53 rd AIAA Aerospace Science Meeting, Kissimmee, FL, 2015

${ }^{16}$ E. C. A. Gallo, L. M. L. Cantu, A. D. Cutler, R. D. Rockwell, C. P. Goyne, J. C. McDaniel, "Coherent AntiStokes Raman Spectroscopy (CARS) in a Dual-Mode Scramjet with Premixed Fueling”, Oral Presentation, 53 ${ }^{\text {rd }}$ AIAA Aerospace Science Meeting, Kissimmee, FL, 2015

${ }^{17}$ R. D. Rockwell, C. P. Goyne, W. Haw, R.H. Krauss, J. C. McDaniel, C.J. Trefny, "Experimental Study of TestMedium Vitiation Effect on Dual-Mode Scramjet Performance and Power", Journal of Propulsion and Power, Vol. 27, No. 5, 2011, pp. 1135-1142

${ }^{18}$ R.H. Krauss, J. C. McDaniel, J. E. Scott, R. B. Whitehurst, C. Segal, G. T. Mahoney, J. M. Childers, "Unique, Clean-Air, Continuous Flow, High-Stagnation-Temperature Facility for Supersonic Combustion Research”, AIAA 1988-3059, 1988

${ }^{19}$ R. H. Krauss, J. C. McDaniel, “A Clean Air Continuous Flow Propulsion Facility”, AIAA 1992-3912, 1992

${ }^{20}$ R. D. Rockwell, C. P. Goyne, B. Rice, H. Chelliah, J. C. McDaniel, J. Edwards, A. D. Cutler, P. M. Danehy, "Development of a Premixed Combustion Capability for Scramjet Combustion Experiment", AIAA 2015-0353, AIAA Science and Technology Forum and Exposition, Kissimmee, FL, 2015 
${ }^{21}$ S. Emami, C. A. Trexler, A. H. Auslender, J. P. Weidner, "Experimental Investigation of Inlet-Combustor Isolators for a Dual-Mode Scramjet at Mach Number of 4", NASA Technical Paper 3502, 1995

${ }^{22}$ C. P. Goyne, C. G. Rodriguez, R. H. Krauss, J. C. McDaniel, C. R. McClinton, "Experimental and Numerical Study of a Dual-Mode Scramjet Combustor", Journal of Propulsion and Power, Vol. 22, No 3, 2006, pp. 481-189

${ }^{23}$ L. M. L. Cantu, E. C. A. Gallo, A. D. Cutler, B. F. Bathel, P. M. Danehy, R. D. Rockwell, C. P. Goyne, J. C. McDaniel, "Nitric Oxide PLIF Visualization of Simultaed Fuel-Air Mixing in a Dual-Mode Scramjet", AIAA 20150354, 53 ${ }^{\text {rd }}$ AIAA Aerospace Science Meeting, Kissimmee, FL, 2015

${ }^{24}$ M. R. Gruber, J. M. Donbar, C. D. Carter, k. Y. Hsu, "Mixing and Combustion Studies Using Cavity-Based Flameholder in Supersonic Flow", Journal of Propulsion and Power, Vol. 20, No. 5, 2004

${ }^{25}$ A. D. Cutler, G. Magnotti, L. M. L. Cantu, E. C. A. Gallo, P. M. Danehy, R. D. Rockwell, C. P. Goyne, "DualPump CARS Measurements in a Dual-Mode Scramjet”, Journal of Propulsion and Power, Vol. 30, No. 3, 2014, pp. 539-549

${ }^{26}$ E. C. A. Gallo, L. M. L. Cantu, A. D. Cutler, M. J. Rahimi, H. K. Chelliah, "WIDECARS Measurements of Major Species Concentration and Temperature in an Air-Ethylene Flame", AIAA 2014-2525, 30 ${ }^{\text {th }}$ AIAA Aerodynamic Measurement Technology and Ground Testing Conference, Atlanta, GA, 2014

${ }^{27}$ S. O’Byrne, I. Stotz, A. J. Neely, R. R. Boyce, N. R. Mudford, A. F. P. Houwing, “OH PLIF Imaging of Supersonic Combustion Using Cavity Injection”, AIAA-2005-3357, $13^{\text {th }}$ International Space Planes and Hypersonics Systems and Technologies Meeting, Capula, Italy, 2005

${ }^{28}$ J. A. Inman, P. M. Danehy, B. F. Bathel, D. W. Aldefer, R. J. Nowak, "Laser-Induced Fluorescence Velocity Measurements in Supersonic Underexpanded Impinging Jets", AIAA 2010-1438, 48 ${ }^{\text {th }}$ AIAA Aerospace Sciences Meeting, Fluid Dynamics TC, Orlando, FL, 2010

${ }^{29}$ R. W. Pitz, M. C. Drake, "Intermittency and Conditional Averaging in a Turbulent Nonpremixed Flame by Raman Scattering”, AIAA Journal, Volume 24, Issue 5, pp. 815-822, 1986

${ }^{30}$ R. K. Cheng, I. G. Shepherd, "Intermittency and Conditional Velocities in Premixed Conical Turbulent Flame", Combustion Science and Technology, Volume 52, Issue 4-6, pp. 353-375, 1987

${ }^{31}$ Y. Li, R. Gupta, "Simultaneous Measurements of Absolute OH Concentration, Temperature and Flow Velocity in a Flame by Photothermal Deflection Spectroscopy", Applied Physics B, Volume 75, pp. 903-906, 2002

${ }^{32}$ K. M. Leung, R. P. Lindstedt, "Detailed kinetic modeling of $\mathrm{C}_{1}-\mathrm{C}_{3}$ alkane diffusion fame," Combustion Flame, Volume 102, Issue 2, pp. 129-160, 1995

${ }^{33}$ J. A. Fulton, J. R. Edwards, H. A. Hassan, J. C. McDaniel, C. P. Goyne, R. D. Rockwell, A. D. Cutler, C. T. Johansen, P. M. Danehy, "Large-Eddy / Reynolds Averaged Navier-Stokes Simulations of Reactive Flow in a DualMode Scramjet Combustor”, Journal of Propulsion and Power, Volume 30, pp.558-575, 2014

${ }^{34}$ K. Ramesh, J. R. Edwards, H. K. Chelliah, C. P. Goyne, J. C. McDaniel, R. D. Rockwell, J. Kirik, A. D. Cutler, P. M. Danehy, "Large Eddy Simulation of High-Speed, Premixed Ethylene Combustion," AIAA 2015-0356, 53rd AIAA Aerospace Sciences Meeting, Kissimmee, FL, Jan 2015

${ }^{35}$ F. Ma, J. Li, V. Yang, K. Lin, T. A. Jackson, “Theromoacoustic Flow Instability in a Scramjet Combustor”, AIAA paper 2005-3824, 41 ${ }^{\text {st }}$ AIAA Joint Propulsion Conference \& Exibit, Tucson, AZ, Jul 2005

${ }^{36}$ L. Kabiraj, R. I. Sujith, "Nonlinear Self-Excited Thermoacoustic oscillations: Intermittency and Flame Blowout”, Journal of Fluid Mechanics, Volume 73, pp. 376-397, 2012 